\title{
WestVirginiaUniversity
}

THE RESEARCH REPOSITORY @ WVU

Graduate Theses, Dissertations, and Problem Reports

2012

\section{Professionalization of Personal Trainers in the Fitness Industry}

Lara M. Foster

West Virginia University

Follow this and additional works at: https://researchrepository.wvu.edu/etd

\section{Recommended Citation}

Foster, Lara M., "Professionalization of Personal Trainers in the Fitness Industry" (2012). Graduate Theses, Dissertations, and Problem Reports. 4853.

https://researchrepository.wvu.edu/etd/4853

This Thesis is protected by copyright and/or related rights. It has been brought to you by the The Research Repository @ WVU with permission from the rights-holder(s). You are free to use this Thesis in any way that is permitted by the copyright and related rights legislation that applies to your use. For other uses you must obtain permission from the rights-holder(s) directly, unless additional rights are indicated by a Creative Commons license in the record and/ or on the work itself. This Thesis has been accepted for inclusion in WVU Graduate Theses, Dissertations, and Problem Reports collection by an authorized administrator of The Research Repository @ WVU. For more information, please contact researchrepository@mail.wvu.edu. 
Professionalization of Personal Trainers in the Fitness Industry

\author{
Lara M. Foster
}

\begin{abstract}
Thesis submitted to the Eberly College of Arts and Sciences at West Virginia University in partial fulfillment of the requirements for the degree of
\end{abstract}

\author{
Master of Arts \\ in \\ Applied Social Research
}

Ron Althouse, Ph.D., Chair

Corey Colyer, Ph.D.

Joshua Woods, Ph.D.

Division of Sociology and Anthropology

Morgantown, WV

2012

Keywords: Personal Trainer; Fitness; Professions

Copyright 2012 Lara M. Foster 


\section{ABSTRACT \\ Professionalization of Personal Trainers in the Fitness Industry}

\section{Lara M. Foster}

The fitness industry is a multi-million dollar business engaged with enhancing or changing the personal appearance of an individual; that is, what Goffman (1963) called with regard to the embodied self, occupations engaged in identity tinkering trades. The muscle and fitness industry's occupations are engaged in tinkering with ones physical identities (Tan \& Brignole, 2012). Personal trainers have been acknowledged in social science literature as "customer service" representatives and "emotional laborers" in the fitness industry (Maguire, 2001). This research is a two-part qualitative study: first, I examine the actions, purpose, and roles of the personal fitness trainer and secondly, I examine the connection between this "protoprofession" and other professionals, para-professionals, and allied health care professionals that comprise the medical landscape. I show various tactics and techniques used by these fitness workers to seize legitimization and take control of their occupation (Abbott, 1988; Collins, 2004). Based on my workplace interviews of them, I attempt to portray the nature of the “contested terrain” related to this occupation’s claims of professionalization. 


\section{CONTENTS}

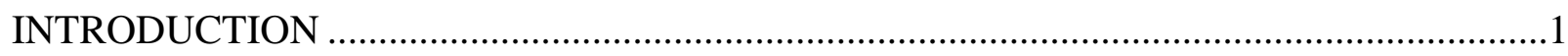

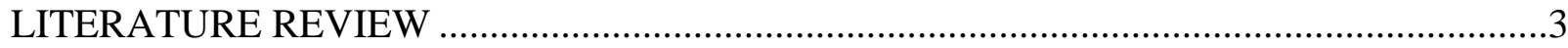

Body and Self: The Embodied Self ............................................................................

Fitness and Fitness Development..........................................................................5

Personal Training/Fitness Profession........................................................................

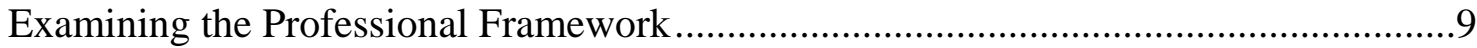

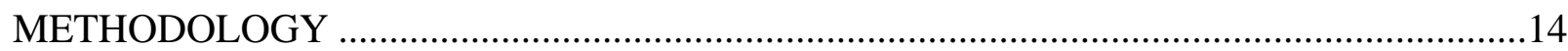

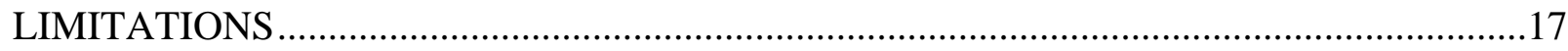

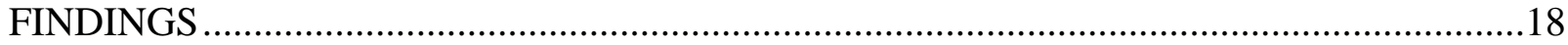

Part I: Defining the Personal Trainer-Finding the Ideal Type ....................................18

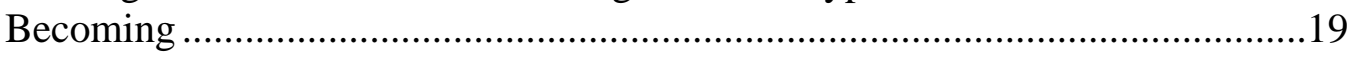

The "Science" of Technical Evaluation .......................................................24

The "Art” of Soft Controls Evaluation ..............................................................28

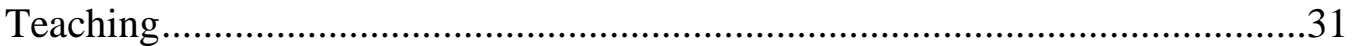

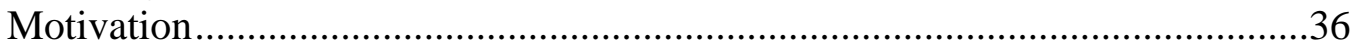

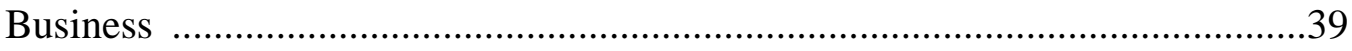

Part II: Inclusion of Personal Trainers in the Professional Landscape .........................43

Micro Structural Mapping.......................................................................44

Macro Structural Mapping...................................................................48

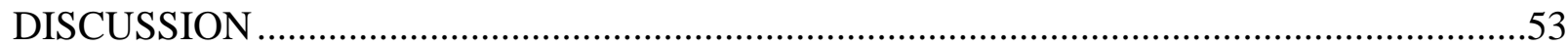

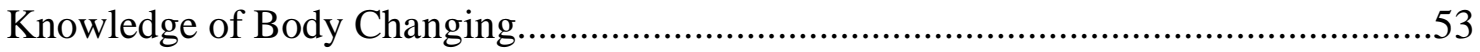

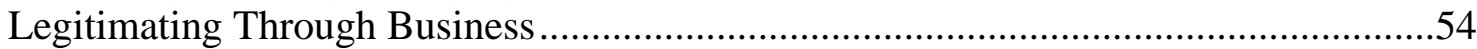

Inter-professional Communication and Context ..................................................59

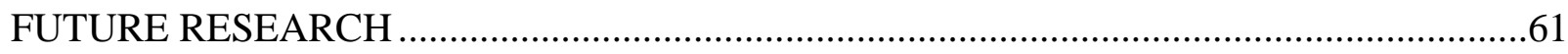

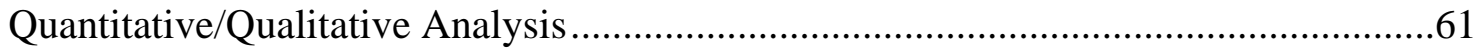

Perspectives of Legal Issues and Business .............................................................61

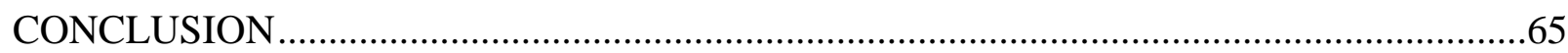

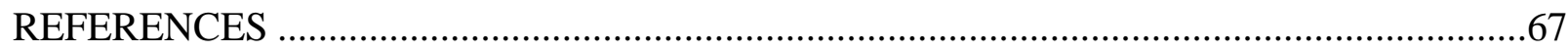

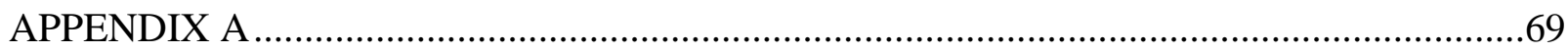

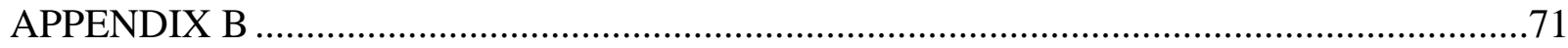




\section{INTRODUCTION}

The past century has witnessed a remarkable development of specialization within the medical profession, not only with regard to specific organs and physical systems but also specialties among doctors that focus in on an array of ailments or body parts such as podiatrist (foot), osteopath (bones and joints), neurologist (central nervous system), and dermatologist (skin). These professions are all a part of the medical landscape engaged in the "control of knowledge” and who, according to Abbott (1988), “dominate outsiders who attack that control.” Each specialty has some considerable jurisdictional control over its specialty in medicine.

I aim to place the “personal physical fitness trainer” in the professional landscape. In order to include the "personal trainer” I first give a history of the development of the occupation. We look at development of the one's bodily identity and how the self is portrayed through one's body to the public and "other." Next in the literature review, I share with the reader the history of fitness and fitness development, noting its growth from that of a mobile workforce to one with growing international recognition in sports as well as health, especially in a context of a “consumer culture” that is widely tied to individual fitness. Previous research on personal fitness trainers shares the consumer lifestyle, and emotional service labor which personal trainers provide as a sector of the fitness industry (Maguire, 2001). Describing those services helps me align the "personal trainer” into the professional “division of expert labor.” (Abbott, 1988)

My findings help me define the "personal trainer.” Interviews lend an understanding of the role, duty, and practices of the "personal trainer" in relation with the "enthusiastic" client/consumer who is guided through healthy practices and personal knowledge in order to change one's bodily condition and social identity. My second question looks at the functions and obligations of the personal trainer, and helps me to locate the "fitness trainer" in the medical 
landscape with other professionals, sub-professionals, and para-professionals. My information addresses how the personal fitness trainer is involved with other medical professionals, particularly with regard to their separate jurisdictional boundaries in the development, promotion, and management of good or healthy bodily practices.

I argue that qualitative research provides more detail and depth of information which shows the reader the ideals of the personal trainers and how they self-identify. Twelve, semistructured, interviews were conducted with identified "personal trainers." While there were multiple respondents identified as being "personal trainers," this research provides data from twelve self-identified personal trainers currently working in the fitness industry. Following Corbin and Strauss (2008), the nature of "personal training” is shown through “each person's experiences, according to gender, time and place, cultural, political, religious, and professional backgrounds.” (pg. 10) The interviews were coded, analyzed, and combined to provide common trends and themes among the respondents that characterize "being" a personal trainer and how they fit in the fitness industry and the broader health landscape. Qualitative research was conducted in order to help identify the different situations encountered in personal training organizations, role of the personal trainer, and how that para-profession fits in the larger social picture. 


\section{LITERATURE REVIEW}

\section{Body and Self: The Embodied Self}

People live in societies that are organized and constructed by meanings developed from social situations. With regard to body and the self, members of our society construct their embodied selves in ways that express the more or less accepted views accorded them by their social groups, and that reflect attitudes and values attached to one's appearance, i.e., "body practices,” that are appropriate and for which one is regularly rewarded or criticized. As social beings, the information we interpret is given to us from our presentation to others (Goffman, 1959). The body is the physical entity - i.e., the person - enacting one’s identity as it is portrayed to the public in social situations.

By and large, the search for better-looking or enabled bodies involves a multiplicity of available rationalized practices (plastic surgery, hormone therapies, steroid driven muscular development, or personal fitness regimens) that encourage men and women to value and to judge their appearance against “cultural stereotypes” that are appraised and often admired by the members among of their circles of acquaintances as well as “others” they commonly meet. Analyzing the body within a context or framework of identity helps us to understand how the body represents the self. Likewise, our understanding of the relationship between the "fitness trainer" and her/his client shows how the "seeking/consuming” individual comes to appreciate the expression of "bodily ideals" and is motivated, then learns and gains the techniques to behave as a "fit, healthy” person; i.e., as a successful consumer (Dworkin \& Wachs, 2008). If we consider the pervasiveness and popularity of exercise clubs, of costly surgeries, of home exercise equipment, then estimate the numbers of men and women of various ages who come from among an array of races and cultural ethnicities, as well as different social classes, then we can judge 
and consider the influence put into motion about body modification and the social significance of society's search for the normal, good, healthy, if not "perfect” body. This concern is not just about good looks, but also about success, longevity, or even valorization of body types, highlighting how over-weightiness, obesity, and other blemished unfitness may be regarded deviant, morally wrong, or even poor citizenry (Crawford, 1980).

Foucault (1977) suggests that we view the body instrumentally, as a thing to be framed to fit the context and identity of clients. I argue that such instrumentalization is embedded in the practices and the program of specialization, and has enabled the growth of the niche assigned to personal fitness trainers. Bodies present the person in every face-to-face encounter in any situation. The dominant or powerful and healthy citizens' label and critique through media, thus shaping consumer culture. For example, indirect control, at a distance, can be cast in regards to fat/obese people as a public spectacle (e.g.: exclusion from certain amusement park rides) and has acceptable discriminatory policies (e.g.: airline price increases for size, higher insurance premiums, etc.). Such bodies maybe stigmatized to identify their deviancy by pursing a change in lifestyle or to continue to be deviant.

The way in which bodies are viewed has changed over the past 150 years. According to Goffman (1963), individuals might accept who they are or they might try to correct an inadequacy by attempting to reshape themselves to fit the norms. In Goffman's terms, individuals engage in processes of identity management. For example, the individual either remains fat, even obese or acknowledges negatively perceived identities, and undertakes a course of reshaping her or himself; that is, giving discipline to the physical body.

In the context of a fitness trainer's command over a clients "self-presentation,” whether a sick body, a socially imperfect body, or just a body, the personal trainer's occupation can attract 
and commonly offer a fitness-seeking individual a "fitness" regimen which frames their quest for new shape, size, or look. Put simply, the "fitness-trainer-as-guru” guides the individual toward building one's body into an instrument framed to fit the image they want to present. The fitness trainer functions in a unique market of services which provides guidance, solutions, and assistance to the fitness-seeking client to gain or regain normalcy in society. Foucault (1977) describes the body as an "instrument” which is controlled to work, or imprisons and limits the freedom that one's body has as their own property. In my perspective, the individual turns the body over to a specific manufacturer/designer market - in this case, fitness professionals - who will provide the entrainment of an embodied identity through routine rituals (i.e., a process of self-problemization and self-reflection) to re-form it into a healthy, fit and disciplined body.

Through initiation into the prescriptions and rituals of the personal trainer, the fitness professional secures a share of control for a person's 'self'; and furthermore, “fitness-in-itself” can now be analyzed as a component in the "ongoing process of cultural production” (Glassner, 1989). The constant comparison of 'the self' to 'the other,' or even to some cultural idealized “imaginary" person, thus provides a process under control. On an institutional level, these transactions can literally come to regard "bodies" as products in the marketplace of the personal fitness industry, using such things as the personal trainer, as well as technologies like fitness equipment, videos, and so on, steer the cultural marketing processes of the fitness professions. Fitness and Fitness Development

In order to understand the practices that physical fitness professionals excel at there needs to be an overall understanding of the functions and jurisdictional boundaries of fitness professions within a larger health and medical landscape (Hughes, 1994; Collins, 2004). I propose that the personal trainer differs from other health professionals found in the medical 
landscape, and that it has produced a new niche market to developing and to serve in. There are separate markets which I will portray that have emerged during recent decades.

The evolution of "fitness" instruction within physical education departments was conceived as a program for public schools to assist youth (boys and girls, alike) in developing their motor skills, cognitive development, and affective (social-emotional) development (Krotee \& Bucher, 2007). Theoretically the body was to be improved, or made "fit” through physical education; in a sense, the body was disciplined during youth socialization through a regimen of bodily development. Even prior to the wholesale introduction of physical education in the early $20^{\text {th }}$ century public schools, the "physical culture movement" had gained a foothold among many private academies in the urban U.S. However, as a “public good,” physical education departments promoted the development of and training for physical educators/trainers which also opened the door to the uses of scientific information to backup the curriculum of exercise physiology (Department of Health and Human Services, 2009).

Indications are that after World War II, during a period that witnessed an array of sports and athletics growing rapidly (e.g., collegiate, Olympic, professional), new opportunities arose for fitness focused trainers to use a set of conjures, plus some skills and real knowledge about the human body. Highly personalized exercise regimens, often fed by wildly suggestive claims, were forwarded to promote new practices reflecting the stylized appearances promoted among practitioners and clients alike. Like the steroid scandals of the early $21^{\text {st }}$ century; such claims were quickly introduced into training athletes as well as various celebrities for competition (Epley, 2000). Additionally, occupation groups proclaimed notable appearances as did their selfpromoting lifestyles, bringing an expression of values and attitudes into play with regard to managing ones health, and of course, pressing the human body into the foreground. Such 
cultural diversity also necessitated specialization for fitness professionals according to specific knowledge and practices (i.e.: strength training for Olympic competition, physical rehabilitation for workforce production, or identity management for the self related to deviancy in one's body).

As the market for fitness opportunities grew, specialized claims of expertise were chartered among several organizations whose clamor for legitimacy were incorporated in an emerging fitness service workforce, thus promoting the basis for practical expertise to develop independently and over time, leading to development of different markets in which fitness professionals could fulfill the demand by applying their knowledge and promoting their skills (professional sporting events, nutritional patterns, obesity, fear of sanctions by society, etc.). Personal Training/Fitness Profession

The lens through which to examine the professionalization of personal training comes from the sociology of professions. Collins (1979) and Manza (1992) show how the evolution of detailed claims by an occupational group is offered to secure the jurisdictional lines drawn within the professional rankings and also divide insiders from outsiders.

My own encounters within the fitness industry anchor my understanding between academic versus non-academic tracks as well as different associational memberships and professional sub-cultures (Lamont \& Molnar, 2002). Organizational credentials, licensing, experience in years, or educational degrees take on distinctive qualifications as part of what make an occupation a professionally recognized community of practice (Hughs, 1994). Most of the respondents in this study gave examples how educational degrees specifically recognized in the field of fitness and personal training give validation to a job, such as degrees in exercise science, exercise physiology, physical education/coaching. Another avenue one might travel to lay claim to expert knowledge is to pass a certification examination which is used to accredit the 
personal training (Abbott \& Eickhoff-Shemek, 2004; Niederpruem \& Sipe, 2006; and American Council of Exercise, 2012). There are, of course, multiple certification associations in the United States, and some have earned international recognition as well, (Niederpruem \& Sipe 2006). However, among the workforces providing their services as the personal trainers, there is no single nationally recognized, mandatory "personal training certification" that assembles the entire practicing labor force.

Among communities of professionals, where state or national regulation, and occupationwide commissions ensure recognition, professional certification can and does function as a virtual "monopoly," assigning "the certified” practitioner a privileged location as well as formal occupational powers. Certification "allots" those privileges and status to members. Collins (1975) notes how 'professionalization' and 'expert' qualifications lead to collegial power and autonomy, gaining a "sacred aura of legitimacy.” For fitness occupations, operating among contested terrains expressed through multiple certifying associations, practitioners are confronted with weakened legitimacy, at least as it applies to the scope of service. Indeed, resentment was shown by respondents in my sample of personal trainers who disregarded, or expressed little regard and concern about certification in the fitness industry.

Experiential learning may be a different route in earning a title or status at a local gym or fitness facility. Someone that has been involved in the field of fitness for years may identify as a personal trainer or a professional. The differences between this person and the academic track personal trainer may contribute to the unstable or inconsistent and contested terrain expressed in this study. As Hughes (1994) notes, “The first goal of professionals was to establish the position of the professional and to separate it from the amateur friendly visitor or reformer.” (p. 41) 
Throughout this research I intend to map out the differences between personal trainers in today's occupational field.

Other ingredients of professional powers can be drawn in relation to how these powers parallel medicine as a comparison of physicians with personal trainers. The American Medical Association (2009) stands as a paradigm group for many organizations that are trying gain occupational status and power. For physicians, a deep lifelong commitment (Hughs, 1994) to the profession usually begins with the undergraduate work, and involves almost more than a decade of studies before entitlement in the profession. As it regards personal trainers, educational degrees may be recommended, but without common certification Abbott (1988) almost anyone can get "certified" as a personal trainer either through "required” programs online (American Sports and Fitness, 2012) or through a local workshops (National Exercise Trainers Association, 2012). My results will draw from Collin's (1975) work on professional communities. The collegial group, for example, of physicians is concentrated within state-board medical/health commissions which enforce licensing, retaining the "power of practice," and ensure that members of the group judge the success and careers of doctors. Practices and control over the personal trainer are vastly different, and affect occupational development. Examining the Professional Framework

From a socio-cultural perspective, as a feature of later modernity, contemporary social theorists typically account for the host of expertise that has emerged to help us to untangle our embodied emotional lives, thereby helping us reach our "full” potential. Among these so-called proto-professionals is to be found the occupation of personal fitness trainer. To this end, the personal trainer is part of what Rose (1999) observes as the "therapeutic culture of self," derived from expert-fed techniques of "self-problemization" and "self-reflection," which is geared to 
measure the embodied self with increasing precision. The power of proto-professions such as fitness training hinges on the creation of therapeutic vocabularies and techniques that offer the means by which to regulate ourselves. In a postmodern Foucaultian perspective, this cultural space is found between the impact of control by public authority and the forms of life adopted by each individual.

Giddens (1991) also shares this perspective, although taking a different path. He insists that risks and uncertainties are an endemic feature of late modernity, and thus the self undergoes massive changes through the reflexivity organized life-span and engages in a continuous narrator of self identity. Consequently, the body too becomes available to be formally worked upon by the influence of high modernity, leading to Giddens’ account of the “transformation of intimacy.”

For this research the data I gathered helps map where personal trainers are occupationally and links it into networks of power and prestige (Abbot, 1988). Semi-structured qualitative interviews yielded information from respondents to re-assemble a portrait of how the "personal trainer” fits in the labor landscape. Interviews also are used to gain and examine encounters, occupational development, and businesses they are a part of.

Abbot explains that professional development occurs when jurisdictions become vacant or there is a "take-over" of other jurisdictions (1988). In mapping the social landscape of the fitness and wellness fields, there is no clear-cut distinction of jurisdictional boundaries - the nature of proto-professional competition. If someone was told to go workout or wanted to get into shape or better health they might go to a gym. Consequently knowledgeable people can share their knowledge and expertise with “clients” who would pay a fee for their services. This is a feature discussed in the new book by Tan and Brignole (2012), “Million Dollar Muscle.” 
They discuss how the multi-billion dollars industry of fitness and muscle, with its emphasis on appearance, has been driven both by market forces and the culture of individual consumerism. The personal trainer is someone who works on the body which, in a sense, puts them adjacent to medical fields. The socially constructed meanings of fitness and the body is how the personal trainer got introduced to the professional landscape.

According to Abbott, "professions" claim mandate and license to practice an occupation which is legally binding as to qualifications and requirements, respectively. Organizational structure comes into play with regard to where personal trainers fit internally into the proto-professional medical network, and externally confronts the fitness trainer with legality and insurance issues. The 'personal fitness trainer' can be hired as trained specialist with 1) certification from a recognized organization; or 2) a certificate from an internet source; or 3) training or educational experience in program related to the fitness field; or 4) as an icon, valorizing personal fitness and acquired 'physique,' to share with others. These paths are indicative of fitness programming within the fitness field. Hiring practices can affect internal competition or foster intra-professional rivalry and controversy. There is no binding "license" or process that requires personal trainers to be tested, certified, or board approved in order to 'practice' to a standard.

Abbot notes professions establish a claim to an occupational field by defending it from competitors, and the ability to reinforce or gain market share by establishing themselves as a single source (i.e., sole supplier), by reinforcing the license and mandate specifying practice and terrain, setting the rules for applying techniques, and ultimately, winning and demanding trust. For Abbott, there is an objective (relating to the object itself) and a subjective (the how aspects of the tasks) feature to professional work. 
A review of literature suggests that a seriously confounding feature of personal fitness training is a convoluted meaning of jurisdiction. For example, professional jurisdiction among medical doctors is broken down into different sub-specialties and practice such as pediatrics, neurology, and chiropractic. The boundaries have been drawn among that field relative to who is in charge over the body/client. My concern is where the personal trainer fits into that landscape. These pockets of legitimacy establish boundaries in which professionals set up their marketplace for development and work (Abbott, 1988). Using Collins (1979), the lines that are drawn within the professional rankings (from educators to the medical field) are established to divide insiders from outsiders. These boundaries are laying claims to jurisdiction, which defines whose job deals with what problems. Claiming jurisdiction according to Abbott (1988) involves the following four steps: 1) assert or insist on exclusive rights to practice, 2) assert the right to selfdefine their work, 3) control of training and entry into the field, and 4) define the license and mandate.

In order to claim and retain jurisdiction, two arenas must be won (Abbott, 1988; Collins, 1975). One arena is command over public opinion, where the profession creates an image and understanding of the nature of its practice to the public. Second, the arena of law which involves the legislative process, upholding legislation, and administration of the law to ensure its practices, this is where the law simplifies what can be done and who can do it relative to professional practice.

To reiterate, the purpose of my study is to examine the context in which the personal trainer's role is constructed, developed, and enacted in organized “fitness” facilities (such as gyms, personal studios, and fitness and sport centers) which are all reflected in Goffman's sense of "ritualized settings.” (1959) Professional education as a "fitness guru” commonly lays claim 
to an occupational mandate and its practices. I want to understand how a personal trainer acts. How does an individual (the fitness trainer) who is knowledgeable about human bodies and who can act upon someone else's body, actually act as a fitness trainer (i.e., design, coach, and evaluate another's body)? At what point, how, and what do trainers profess to know about the "other's" body and how to transform it; in other words, how do they "motivate" and "teach" fitness? How does the trainer assess a client? Finally, I will explore how the growing attempt to professionalize their practice influences their practice and authority in the health/fitness community. As mentioned previously, building upon the production of this cultural phenomenon of the body, a proto-profession of "personal trainers" is being developed. As repeated by Glassner (1989), “Moreover the fit body holds a signal position in contemporary American culture — as a locus for billions of dollars of commercial exchange and a site for moral action (Stein, 1982; Crawford, 1984).” (p. 180) 


\section{METHODOLOGY}

My interest in personal trainers comes from experience within the field itself. My work as a "personal trainer" led me to focus on and attempt to understand different certifications and career opportunities in this occupation. Desires for understanding led me to use qualitative research interviews as a strategy to probe personal experiences and obtain information through trust and caring disclosure about the subjects’ occupational careers.

While qualitative interviews were chosen for this project to collect information from "personal trainers" in face-to-face encounters in the community, I used a snowball sample approach that relied on a few known contacts to assist in locating twelve (eight male and four female) willing respondents for the interview process. These semi-structured interviews (see Appendix A (Interview Sample Questions) provided an inside look at the personal trainers’ occupations, their perceived job roles, and their effects on the professional landscape. These conversations enlightened me on the occupation of the personal trainer. Analysis of the data revealed the personal trainer occupation within the professional landscape as an emerging protoprofession of the medical landscape.

The interview settings ranged from 38 minutes to 78 minutes, four of 12 interviews were longer than 1 hour. Each audio file was transcribed by the researcher in order for qualitative coding to take place. The interviews varied due to the work schedules of the respondents; most fit me into their "personal training" daily work when I contacted them about my research focus. Five interviews were conducted in the offices of the personal trainers; two more were conducted in the gym facility with the radio on and gym members exercising. The environment of a gym or fitness center did not provided ease in collecting data on multiple levels; as a researcher I sensed the issue of respondents sharing data or lack thereof because of workplace issues (clients who do not know the secrets of personal training might have been present in the interview setting). 
Complete ease in sharing data might have been shortened or abbreviated during the interview process with Respondent 4 with the case of one of her clients entering into the room of the interview and her "coworkers" coming and going from the functional office-the place where personal trainers take their clients to do the "medical history reports and goal setting." These settings and interruptions not only placed a burden on me as a transcriber (shuffling through the noise of the audio recordings) but could have possibly affected what the respondents shared with me throughout the interview. Two interviews were made by the telephone, one because of the distance, the other later after the workday of the respondent (this took place at 11P.M.). One interview was conducted in my campus office, accommodating the recent un-employment of one personal trainer. The last interview, which nearly took three months of calls to accommodate schedules, was made in the respondent's home. The interview procedures were the same, with the respondent and me in the one-on-one dialogue. I based my questions on an interview guide but let the clients' answers to the first few questions take me where their responses engaged in discussion.

Qualitative interviewing allowed me to see the actions of personal trainers through depictions and stories of their experiences. Much of their work reflected the practices they employed in encounters with clients, and practices were routine actions that directed clients toward self-monitoring performances. My work as a "personal trainer" at local gyms provided grounding in observations of people as physical beings moving in space, observing the contacts between them, sharing in encounters - the talk and performances - between clients and trainers. Like most interaction, the encounters and dealings are reinforced by what Goffman (1959) called "substantive rules" which guided interactions. These observations, of course focused mainly on indoor settings within an arena where impressions are managed (like a school or workplace). It's 
focused in a way to "look good," to show off qualities in situations where one's personal space is prepared for them.

During the transcription phase I noticed recurring themes throughout the data which lead me to write "memos" on the context. This helped me to combine the data, and guided my analytical thought processes, which lead to "aha!” moments in conceptualizing the actions of personal trainers and the occupational attempt of professionalizing. During the "data digging” I used my "intuition" in coding the data and also used knowledge of the "action/interaction" the personal trainers were sharing with me in deciding what to share with the reader (Corbin \& Strauss, 2008). The following thesis represents the shared stories which combined help share answers to the researcher questions of what a personal trainer is and how they fit in the professional landscape.

While there are no quantitative survey results, there is literature supporting the occupational development and growth of the fitness industry. I wanted an insider's perspective on the occupation itself through those who practice the techniques in their everyday lives. As Abbott (1988) shows in his work on lawyers and medical doctors, I wanted a better understanding of the actions and physical context that the personal trainers actions were enclosed within. The personal trainers' experiences varied with regard to education, occupational development, facilities and environments, and clients/consumers who they work with. It is very important to examine Appendix B (Extended Profiles) to gain better comprehension of the respondents that were interviewed. To maintain anonymity the respondents were assigned pseudonyms and organizational affiliations are mentioned in the descriptive profiles. 


\section{LIMITATIONS}

Critics can question the limits to generalization based on a dozen respondents. I would agree with them, but my main purpose was to understand the developing professional occupational structure. During the interview process, listening to fitness trainers talk about themselves, it was their experience and their "knowledge" that surfaced even though I knew some of the techniques already. While objectivity is vulnerable in qualitative research (Corbin \& Strauss, 2008) as a researcher I trust myself to make the right decisions throughout the analysis, not to mislead readers or to subvert the data but to tell the story of these personal trainers through their own accounts.

In order to show how the occupation has grown into a "proto-profession," further future research should added research could examine the clients who seek the services of personal fitness trainers. In addition, attention needs to be directed toward the leaders/owners of personal fitness training organizations, and other proto-professionals in the muscle and fitness industry gain both perspective and to continue the discussion on the occupational development (Corbin \& Strauss, 2008). 


\section{FINDINGS}

\section{Part I: Defining the Personal Trainer-Finding the Ideal Type}

My observations are organized into two tiers of questions: 1) what does a personal trainer do, and 2) how do they fit in the professional (medical) landscape? First I describe the evolution of personal trainers as social actors, as a role playing self. The typification is not a single description of the "ideal” trainer, but rather it represents the information and language my respondents used to define themselves. The following diagram depicts the personal trainer and what defines them:

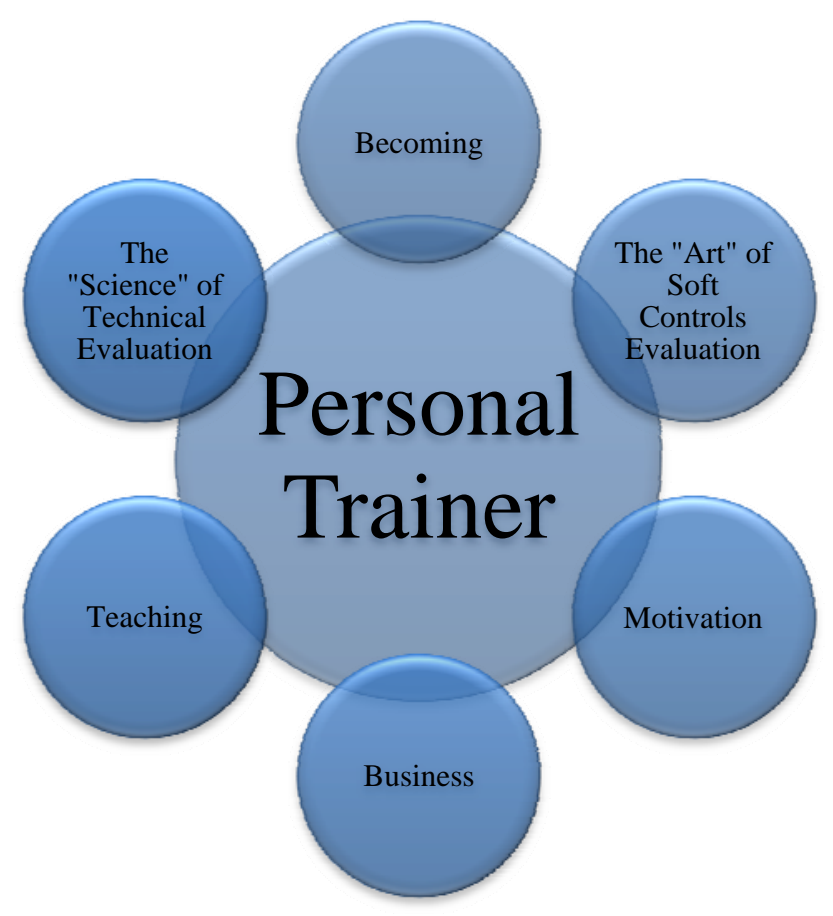

Professionals claim to possess "esoteric" knowledge about a topic or practices, and it is this practical knowledge that differentiate the "fitness" professional from other professionals and "lay people.” (Abbott, 1988) Personal fitness trainers claim knowledge pertaining to altering, fashioning, or improving a body, as a whole or in part. Applying their knowledge, identified as techniques, enables the personal trainer to manipulate the clients' bodies. The specific strategies 
used for applying these techniques are derived from technical evaluation, social evaluation, teaching, and motivation.

\section{Becoming - Evoking Occupational Development}

The following section introduces how one engages in the occupation of the personal trainer. Three aspects compromising the personal trainer's occupational development include one’s personal history, education, and getting experience with fitness or experiential learning.

\section{PERSONAL HISTORY}

Generally respondents mentioned their own physical activity and sport participation as an influential aspect of their interest and growth. For example, Paul felt that being in sports "pushed” him toward fitness,

I just like lifting in general. I always have in high school I was always lifting weights, and playing basketball football and sports like that so I think being around sports kind of pushed me in this direction a little bit as far as my decision to become a personal trainer goes.

Timothy's window is all-encompassing:

Because I really was, I mean I'm, I've been in exercise my entire life and I wanted to do that and I've kind always said I wanted to be a trainer.

As a veteran to the fitness industry during the pre-Title IX era, Kathleen said the support from family and friends helped her love for fitness grow.

Well, I’ve always loved fitness my entire life. My parents were very very good role models. And I was born back before Title IX you know so there were no sports for me. None at all. I had a lot of sisters and brothers. Like six in our family and we were introduced swimming, skiing, umm biking, tennis. I was my type of active sports we did all of our lives.

As seen in the profiles three male respondents Timothy, Matthew, and Andrew, all commented on how their interests in bodybuilding lead to “competitions and certifications” related to their 
occupational and personal development. Andrew has spent many years in the field of fitness and mentioned the foundations of his education,

... Back in the 80s I spent every year in California with, in a Joe Weider's clinic with exercise physiologist that work with pros, umm, coaches for the Olympics that gave seminars and worked with us. Ah, Mr. Olympia's. All the top athletes in the world were there. Ate breakfast with them, stayed in dormitories with them for weeks on end and got first hand information from them. That's, I think again with your question about how I differ, is I don't think there's too many people that can say 'Yeah, I've sat through exercise seminars with Arnold Schwarzenegger and have met and sat through things with Joe Weider, publisher of Muscle and Fitness Magazine.' Probably the most popular name in body building are those two people.

Much younger, Matthew listed his education backgrounds and the certifications he acquired as the path to the present.

Strength Coach Certified through the (organization concentrating on conditioning and athlete development) and a Personal Trainer Certified and a Certified Bodybuilding ah, Contest Readiness Coach. And ah, basically I apply everything that I've learned through each one of those avenues.

The respondents present a biographic roundedness revealing an intermingling influence with

fitness and sport from adolescence prior to stepping up to the next level of gaining and processing somewhat self-centered knowledge which gets amalgamated to feed their interest as a fitness practitioner.

EDUCATION

Another step was the acquisition of information within higher education. Timothy expressed his route like this:

Ever since I was young I was just kind of ah, really into working out. So I actually took an honest profession and got my undergrad and graduate in exercise physiology. 
Paul started in a business program, and then went to an exercise science program because of costs and effort he spent practicing moves and playing football,

I actually I played college football. And coming in as a freshmen I didn't know what I wanted to do really I was in the pre-business program. Playing football and lifting weights and everything like that really got me into strength and conditioning. And from that point I switched my major into exercise physiology and got my undergrad in that and then I went on and got my Master's in Education in Coaching Athletics.

Bradley mentioned taking a "personal training class" during school which influenced getting his “undergrad in Ex. Phys.” (Exercise Physiology) and another in "health science;” which he then clarified the differences between the two,

Health science had to deal with health like umm different kinds of diseases. Exercise science is physiology behind exercise and what cells and bones and muscles do. And health science has to deal with health, mentally, physically, and spiritually, and psychologically.

This statement either aids or disguises the routes to professionalization for the personal trainers because it offers so many avenues.

A core notion garnered from the respondents who mentioned higher education as a means to their esoteric knowledge base is completion of multiple degrees and/or graduate education. Jane is one of the two interviewed who is currently working on her "dual degree in Exercise Physiology and Athletic Training." Sarah shared the following when asked if certification and education really matter,

Yes, it does. Now here's the stipulation with personal training that I have a really big problem with. To be a personal trainer technically you have to be 18 years old, hold a valid CPR certification and take a test that "certifies" you as a personal trainer. Now there are a lot of hokey organizations out there on the internet that you give them $\$ 50$ and you are a certified personal trainer. Let me tell you what. If an 18 year old goes out there and does that they're gonna hurt someone. They're gonna hurt someone very badly. So, here I am with two degrees, three certifications, 5 years of experience and I consider myself a really good trainer. 
For Sarah, there is a divide or at least an abject stance on what defines the personal trainer and how they acquire their knowledge. Kathleen was a big proponent on teaching and education related to personal trainers and their knowledge, “...my undergrad is in Physical Education Teacher Ed. and Health and then my Master's is in Physical Education and Teacher Ed.”

During these interviews I uncovered disagreement between those trainers who related to their education and proto-professional skill level (proto professional is defined as a soft profession/occupation such as message therapy, where the para-professional is one who serves other professionals, such as a para-legal) skill level. Carly imposed:

I think with my athletic training as well as my strength and conditioning background and the fact that I actually have a degree in what I do as opposed to most personal trainers.

Carly has a Bachelor's in Exercise Physiology and a Master's in Athletic Training, and complements this with being a Certified Strength Coach. Her response to education differs from Andrew who has met with and learned from "popular names in bodybuilding" over a career lasting two decades in the fitness. Andrew does not get a higher educational degree in a fitness related program but had different ways of gaining practical knowledge by working within the sphere training, under various mentors and doing "exercise seminars.” Continuing to scan trainers who did not receive higher educational degrees, David concedes that he took "just a class" on personal training when he was working out at a gym, and establishes that it was "more for me," packing-up his own practical experience. When he was "offered a job” at a gym, he told me how he acquired more knowledge from his mentor at that time, his boss, “...and showed me some things he had learned in the 20 plus years he has been training people and running a gym.” Like David, Andrew also knows fitness by showing it and doing it, the ways they 
acquired fitness from their mentors. These two respondents represent a part of the spectrum of personal training which is undefined and likely unrefined.

\section{EXPERIENTIAL LEARNING}

Throughout our interviews made a broad array of connections between and among education, knowledge, and professional development, but all of them expressed themselves through experiential learning, performing their knowledge, often enough with uncommon competence, guiding the training of their clients with the common sense of experience or the trials and error of personal training. Most mentioned continuing to learn from "people in the field," or "mentors” and "veteran trainers.” Most shared in the belief that just because you have a degree does not mean you are a good personal trainer. One respondent mentioned that you could have a “trainer who graduated in exercise physiology that doesn’t work out” and that is what made him, the fitness trainer I was interviewing, unique compared to other trainers is his

“floor experience.” (He could see and show what mattered). When asked if trainers had a magic wand, these fitness trainers suggested some sort of “internship” to develop future personal trainers.

Personal trainers gain practical "hands on experience” playing the roles that they are supposed to abide by. This perspective can be seen through the eyes of Kathleen, who is a teacher in personal training:

Yeah the science of the personal training is knowing how to do everything. Knowing how to do a step test and to do a blood pressure. Then the art of personal training is really, can't be taught. It's how well you work with the client. Communicating with them. Building rapport with them. Because I've had, oh my gosh I've been training trainers for over, aw, probably for the past 15 years, and I've had trainers that really excel in the science part, I mean they know everything about everything but they can't work with people. 
John offers this advice about people who want to become personal trainers, that they not only need an understanding of the body but also find methods about how to communicate to clients,

I mean you have to be either certified or you know have a degree in something that is relevant to that and have some kind of knowledge to be credible with what you are doing. And ah, you have to have some type of experience. I mean, you, somebody that works out all the time and you know, it's worked for them, however bulked up or they have great cardiovascular strength, that's some type of experience that you could use if you came to a job and started to learn. Like I said before there are other skills that you have to be able to do. Communication skills and just being able to, what I was saying, like it may have worked for that person, and that's good experience but you have to know what else you can do to tailor it to the person you are training.

Trainers really are the role they are playing. They value and treat clients with respect.

Much activity comes to be in 'character' because performance and appearance merge into a well manner, well-played relationship. John explains how “communication” is a key feature:

Like I said before there are other skills that you have to be able to do. Communication skills and just being able to, what I was saying, like it may have worked for that person, and that's good experience but you have to know what else you can do to tailor it to the person you are training.

These reflect the difference between technical evaluation ("science") and soft controls evaluation ("art") of clients.

The "Science" of Technical Evaluation

During this research respondents mentioned training evaluation that was technical (i.e., detailing works with the body); this "science" is the rationalization of the body as a controlled object. Two processes are key to the technical evaluation by the trainer: the objectification of the physical body through "exercise testing” or legitimizing and the after action profile. The physical evaluations are derived from exercise physiology based examinations, along with "basic" measurements such as height, weight, and body fat percentages. As mentioned these 
measurements are also ways to channel control of embodied selves, and provide the rationalization of the body through various 'metrics.' This objectification is mindful of the anxious self-scrutiny that Lasch (1991) proclaimed when he argues that performance and its measurement (erotic, intellectual, emotional) are exploited. Trainers emphasized different forms of technical evaluation which is one aspect of the procedures in "base-line testing."

Technical evaluation was the main point of testing that Bradley had in mind when he mentions the "basic pre-test...like a total body workout...I kinda see how your body adjusts to the exercise and neurological adaptations of your body.” This total body workout can vary from one client to another fitness client depending upon the trainer's philosophies. For example, at Paul's center, they do "VO2s on every single client.” Clients are attached to machines and computers, calculating computerized readings. Paul showed me a computerized treadmill which has a breathing apparatus and a set of electrodes (patches that are placed on a client's chest to measure the "correlating heart rate”). Other personal trainers mentioned the importance of basic pre-tests, featuring basic measurements of body fat and heart rate. Matthew, for example recited a list of different technical tools used to measure body fat of clients "circumferences, skin folds, bioelectrical impedance, bodpod, dexa.” He also cited levels of achievement under routine and optimum conditions defined at, “65\% of their max they should be able to press a weight for 15 repetitions," which determines a baseline of muscular endurance. Zack does a testing of his clients walking on the treadmill, usually while he gathers heart rate measurements. Two weeks later he retests, usually "their heart rate is like five beats less” which is one of metrics that helps to focus the clients working on the program (a constant measurement and evaluation of progress or failure). Many personal trainers mentioned how they use soft evaluation to talk to their clients 
in order to measure some sense of technical evaluation about how their clothes fit on their bodies.

\section{LEGITIMIZING}

One of the interesting points of technical evaluation is the determination of who can perform certain metric testing. Sarah mentioned how she "refers" her clients to another personal trainer within her respective facility, if they want certain testing done, "he does a lot of testing that I don’t do so if I need someone who needs a metabolic test I will refer them to him.” Another example of metric jurisdiction comes from Jane. She gave a detailed description of the testing with "sub-max" procedures they use at her respective facility because they are not educated on the maximal effort testing procedures,

Sub-max is just you're getting a range, of like muscular endurance. Like we would do pushups until they are fatigued or their posture fails or their technique fails. But a max would be a one rep max.

Kathleen explained testing procedures with a "two minute step test” but if a client had a bad knee then she would modify the tests to a "12 minute Cooper Walk/Run on the treadmill” all depending upon the client's ability and fitness level. This shares the adaptation that is required in the personal trainer's repartee.

Technical evaluation happens on a time continuum in the personal training of a client.

Several respondents noted the repeated technical evaluations takes place throughout the different “phases” of a client's program. Support for these adjustment techniques, not only in testing but in the rituals of exercise, is another aspect of professional legitimization. Matthew shares the following of constant technical evaluation and practice:

I know what to do when someone has a condition like arthritis. You can't work someone with arthritis like a bodybuilder. Their joints will get all inflamed and you'll do more harm than good. I mean you gotta go kinda 
heavy with them and take the volume down with someone with arthritis. With someone with diabetes you can’t be doing high intensity cardio with their metabolic disorder will effect that and it will do more harm than good. The typical trainer doesn't know that stuff. And they'll just help them when they get on the treadmill and run or whatever and not knowing that they might be doing more harm than good.

A "program," according to David,

Entails coming up with exercises or certain workout plans, the length of the workout, what you do on the workout, how often you come and workout, and what you do in those workouts.

These "phases” last anywhere from “4-8 weeks” and vary depending upon the client’s physiology and one's attention to the program. David accounted for the connection between technical evaluation and soft evaluation as a matter of,

Understanding what problems they (the client) have with what exercises they're working with that way you can change their program to make it fit so that they will not be hampered by not liking a certain exercise.

Carly shares the need for soft evaluation along side of technical evaluation at the beginning and throughout the training processes,

Personal history as well as medical history as well as pluses and minuses and kind of incorporate that into their program so therefore they are doing things that are very individualistic towards who they are and what they want.

\section{AFTER ACTION PROFILES}

Another side of technical evaluation is administrating and planning of programs for the clients. There are "folders" and "paperwork" procedures (i.e., files that depict the person/consumer) that get completed in order to provide personal training services. Four actually mentioned "Par-Q" forms and one gave me a copy of the form that is given to their clients to screen medical histories. This form is developed by the National Medicine and Sport College (NMSC), which according to the trainers ranks as one of the top organizations for personal trainers, exercise, and fitness. Kathleen clarified the importance of this organization, 
"They set the guidelines and other industries follow those guidelines." Review of previous workouts helps the personal trainers to evaluate how the client is progressing on the phase and "logs" or "folders" help in evaluating the program design and implementation.

The more experienced personal trainers said the use of the term "prescription" was not allowed because of the jurisdiction implied by medical doctors. This aspect of the technical evaluation goes directly to the heart of the power of personal trainers in the professional landscape. In reference to the difference between prescription and program design Kathleen shared the following:

We implement programs for clients and its different legal jargon...It's basically the same thing but you just can't use the word prescription because if you use the word prescription then it basically sounds like you've diagnosed something so this is what you are prescribing.

John, who is an undergraduate in training and exercise physiology casually uses the term in the following statement, he explains most of the program is designed around the client's needs and wants,

You impose your prescription and all that but you need to go by what they want to do...It's not really any difference in the word. It's just how you're using it I guess. Drug prescription you have to say two pills here on Monday and one pill on Tuesday. That's kind of what you are doing, for this exercise you're going to do 3 sets 10 reps. For this exercise you are going to do 3 sets 12 reps. You are prescribing the exercise.

While technical evaluation and program development are clearly influential in the process of acting as a personal trainer, they represent a portion of the entire spectrum of being a personal trainer.

The "Art" of Soft Controls Evaluation

Technical and soft evaluation goes hand-in-hand for most of the respondents in this study. There were a few trainers such as Sarah who emphasized a completion of the preliminary 
soft evaluation before any technical evaluation takes place. She mentioned how she sits down with the client and asks why they are coming to her for personal training,

Well, it’s, I’m very goal oriented. So before I start working with someone I sit down with them and I say, 'Alright, tell me why you're here. Tell me why you're coming to me. Tell me what you would like to get out of this.' And then based on what they say, what their goals are that's how I base their training program.

The importance of this soft evaluation is part of the personal trainers becoming, in the sense as a personal trainer you “....really have to listen to your client. You really have to understand where they are coming from, what they want.” The data I gathered shows there are different "hats” that personal trainers wear in their occupation. One of the hats was the comparison of personal trainers with "bartenders," a person who "sits down and listens to you." Other comparisons of personal trainers related to the social or soft side of evaluations were "hairdressers" and even a "life coach" but related to fitness concerns.

Paul presented the trainer practice this way:

Also personal trainers sometimes serve as therapists. A lot of times you have a client that might have had a really bad day and they come in and they really want to vent to you... which I enjoy because you get to meet a lot of different people and you get to hear a lot of interesting stories.

The personal trainers held strong beliefs of needing to listen to their clients on a daily basis to understand how they are "feeling" during the session in order to get the most out of each workout together. This soft evaluation takes place throughout the workout sessions. At the outset, "seeing how their day is going," during the workout if they "like the exercise" and are "happy" with the program and at the end with examining how they feel after the workout, all are soft evaluation periods.

Paul shares the daily rituals of working with many clients, who pay for his services and their needs for a certain product/success, 
Updating clients workouts they might wanna change something, or they might not like a certain lift, some cardiovascular exercises that we do with them, so I make changes to that and then I also have to make new workouts for those that have ended their sessions and are continuing on. I make up new workout sheets for them, put a little more variability in there, switch up things and then that way it stays interesting for them.

David shares the customer service aspect of soft daily evaluations,

Uhh It's good to listen to what they're having problems with. Complaints that they're having. Umm as they're going through the exercises especially if they've already been doing it for a little bit, you want to make sure you understand what problems they have with what exercises of where they're working with that way you can change their program to make it fit so that they will not be hampered by not liking a certain exercise. They know that they can change around and still enjoy their workout because they're able to do a bunch of different exercises and do stuff they really enjoy. That normally makes them come in more and achieve more success. That they're actually excited to do it and enjoy.

Continuing with soft evaluations, Bradley mentioned the modification of exercise and working the client up towards larger movements if they do not feel comfortable with a certain lifting exercise,

I try to put together a group/program together that is fit to the goals. And we'll kinda go through and say okay I made this up for us. We're gonna run through it if there is anything you don't feel comfortable with, if there is something you don't like, please tell me. If you don't give me the verbal talk or the speech that tells me you like the program or you understand. Then they'll tell me 'well,' I'm like 'hey let's try this' and like 'I'll give it a try' and they'll do a leg lift and then 'I can't do this.' So I substitute in, we'll come back to it, we'll work on this stuff that can help on that movement, whether it's a pull-up or a lat pull-down. We'll get you back up to that level.

John (personal training student) mentioned with that clients are welcome to come in and he would help them out with the programs or questions, even after he is directly finished with the clients (i.e.: their schedule number workout sessions).

If you ever need any help, if any of my prior clients need help with even changing up an exercise plan, like if it's getting old to them and they just want to talk to me real quick about what to change, you can do that 
anytime. But if you want to like check body fat or do an assessment we can, I mean you can if I have time you can schedule one and we can check everything.

For some respondents, like Kathleen, evaluation at the beginning of the client's process of working with a personal trainer really concentrates on "goals" of the client and working on "setting realistic goals" for that client. The following shows how important "goal setting” is to the client and the personal trainer:

If someone comes in and says 'oh I just wanna lose weight.' That is just a generalized goal. To make it a SMART goal it has to be specific, measureable, attainable, relevant, and time bound. So that means that they come in and say 'oh I wanna lose weight' then you would give them a specific, 'I wanna lose 10 pounds.' Is it measurable? Yes it's measureable. Is it relevant? Yes it's relevant. Umm, ah, time bound. You could say 'I wanna lose 10 pounds over the next three months.' So that's doable. I mean, some of them will say 'I want to lose 40 pounds in three months.' That's not doable. Not realistic.

Smart goals are befitting because they reflect the menu laid out for the client. The proceeding accounts shows why it was "not realistic," and Kathleen as well as other respondents commented on the ability of a human body to lose weight and keep it off for a safe amount of time, as “ $1-2$ pounds per week.” While these goals are soft they directly relate to the technical side personal training.

\section{Teaching}

Attention to teaching and to motivation introduces relevant elements of performance for the personal trainers. For trainers, providing the client with continual knowledge of the purpose, exercise movement, and exercise programs allows trainers to take on the role of a teacher. Each trainer mentioned the need for teaching the clients "proper mechanics" in order to prevent injury and to target certain aspects of the exercise program to ensure that the clients could learn about effects of the exercise and what muscles/systems are affected. 
For instance if a person can't do a lunge properly. They can’t do a walking lunge. What you do is you just break it down in the simpler steps. (Paul)

But at other points anytime if I'm sitting there or my employees were sitting there I would encourage them if one of the members came up and asked them a question on how to do something or proper form or something, that they would assist them because if they achieve their goals that's going to be a positive reference for everybody else and that'll bring more people in. (David on daily tasks)

Bradley (on what a personal trainer does emphasizing his actions) Helps motivate individuals and helps to teach them the proper techniques to make sure they are performing it right.

You want them to get that right technique and ah, cause there are some things that don't take a lot of technique and there are other exercises that take a lot of technique. And by the sixth session you really want them to be able to do it on their own so when they go off they are not doing it wrong and not getting the proper workout that they were getting. (John in regards to teaching)

Andrew shared a story of a time he was at a seminar on the "proper form of squatting," and he critiques the teaching methods used by the seminar instructor. This quote also challenges the notion of "proper mechanics” advocated by many personal trainers in the research:

...And his is all text book. He weight about 98 pounds at six foot two, but his was all text book. How the spine works, how the hip works, how the knee joint functions, and how to align all these to get proper form and technique. And one of the questions that arise from that seminar was that a pro-body builder had asked that professor had he ever been in a gym and tried to do what he said, 'Well no I haven't'. 'Well let me explain something to you. When you slap 600 pounds of weight on your shoulders your spinal column changes structure. Your hip changes structure. Everything changes. So yeah what you're putting on paper looks great but the reality of it in a facility or in a gym, or when you have 600 pounds on your back, that will not work.' So it's more a trial and error and experience over time that makes you, I think, what I feel is a good trainer, is someone that can communicate with people, let them enjoy what they are doing, don't speak over their head, and get them educated in what their goals are. 
Timothy, mentioned clients do not understand how to do things properly,

That's another thing to a lot of people just come in and ah, they're not doing things properly. They have, not that they will get injured but they have a higher potential of getting injured doing the things they do. They have a higher potential of overtraining or under training.

Matthew, also mentioning clients harm with improper methods,

For example, if they have certain type of disease like diabetes or arthritis or high blood pressure, they just can't come into a gym to do a workout because if they do and they don't do it correctly under the proper guidance they might ah, harm themselves.

The nature of teaching was a contested among trainers because some felt imparting too much knowledge would challenge the occupational power over the clients/consumers while others emphasized the importance of imparting a more holistic understanding to a client so they could manage their own bodies after a certain time. Carly had this philosophy in her teaching,

I think I'm different also, also working in this small city, this small town, I try to educate people so eventually they can do it on their own as opposed to most personal trainers who don't want to individualize it too much so therefore you always need them. I don't think that that's fair but that the mentality for most or they wouldn't have the job.

Matthew, concerned with his business practice took the opposite position to applying his knowledge to production of a fit body and to keeping clients/consumers coming back;

I'm not only a personal trainer. I'm also an exercise physiologist and nutritionist. So basically I have separate rates. I mean, I'm not going to give them nutrition for free... But if you're getting someone results and continuing to teach them, they'll want to keep coming back for more.

Teaching for the personal trainer is an ongoing process from the beginning of the trainerclient relationship. The first "consultation" or interaction the client has with a personal trainer is a mixed social and technical evaluation. This “consultation” provides the needed history and indicates legality procedures the personal trainer needs in order to proceed with designing a program for the client. The history would be protecting the personal trainer along with the 
client's health, (just like the previously mentioned Par-Q). In the following Bradley describes the consultation with a client:

I'll do like an interview and I'll have them fill out like a medical history form so it tells me if they have two or more risk factors, two or three. It tells me that certain factors need a doctor referral. So that tells me kinda liability, not a liability kinda liability issue but kinda like okay. I need to get a doctors referral so that kinda covers your back.

During this consultation there are different aspects of teaching the client that it will take dedication on their part to complete the workout regimen. Initial imparting of knowledge at this point differs among the respondents based on their specialties. Categorizing these specialties help arrange the professional landscape of personal trainers; the categories are physical training, nutrition, and health and wellness. Respondents were mixed and subtly divided on the concentration of knowledge that they teach to the client.

There were four trainers who spent most of their encounters sharing knowledge on the physical aspect of technique and more holistic physical educating that goes along with personal training. Sarah shared the following information,

Yeah, you are just constantly teaching. That's what your job really is. You're teaching people how to exercise, umm, the right techniques, how to combine exercises. Umm, different ways to get the results that you want so it really is teaching, it's constantly teaching.

This teaching of the physical aspect of the training can be seen step-by-step process David uses with his clients. Step one was to "assess the client” through technical and social evaluation, step two was to "design a program" or workout, and finally,

The third part is to show and demonstrate that program to them, so you explain how to do the exercise. Show them the exercise, explain what the reasoning is behind it, and give 'em an overall understanding that way they're not just sort of following you blindly. 
Physical demonstration of the exercise goes hand-in-hand with the art of communication as well. David also mentioned the "technical mumbo-jumbo" or names and definitions of body parts and movements, so he tries to say "everything in terms that they understand." Translation of esoteric knowledge to layman's terms helps the client understand but also opens the boundaries of knowledge.

Five trainers placed emphasis on the "wellbeing" and "fitness" of clients instead of concentrating solely on the physical manipulation of bodies which personal trainers share with clients. This division of personal training almost takes a holistic approach to wellness. John mentions that when he gets clients into workout and they are happy, successful, and keep coming back, that this exercising “...could change anything within your life.” Lifestyle changes are also seen when Zack noted to me, "I try to use as much objective information at the beginning that I can to show them [the client] how fitness can change your life.” Then he goes on about how he shares his knowledge by bringing "basic physiology to the table" because he wants to "go to medical school" and this sharing of his knowledge in personal training helps him practice for medical school. Sharing knowledge about overall fitness and wellness had a reoccurring theme among the respondents who mentioned this philosophy of personal training (removing body terror of aging/health/success). The theme was to educate and "train" the clients enough so that they can "go out and do the exercising on their own" and take care of their own bodies/selves and if the clients have questions personal trainers will either set up a "session" or "mix up the program" for the clients.

During the interviews only three personal trainers mentioned their specialties focus on nutrition, and one commented on its value to success and business. Nutritional planning and control is one kernel in this guidance, but there was also an underlying concern with "the 
customers" as a business theme present for the trainers who introduced nutrition. In regards to teaching about nutrition, Matthew commented that he educates clients on reading food labels, measuring foods, and making nutritionally proper food choices. Andrew (who runs a nutritional business along with his personal training business) and Sarah strongly advocated that foods and nutrition had more of an impact on the physical body than did actual physical exercise. They said there was an " $80 / 20$ divide," meaning the changing of the body depended $80 \%$ on the nutritional intake and $20 \%$ on the physical workouts. They have consultations with clients and teach them how to use food to change their bodies. While not identifying specifically with nutrition Jane, the student personal trainer, mentioned that she recommends literature, The Eat Clean Diet (which also has the rule of 80/20) (Reno, 2007) that she has used in her own life that has "helped her help her clients.” Zach even acknowledged, "Nutrition is $60 \%$ of it. You know, if you are working out that's all well and great but if you are eating awful that weight is going to come down an awful lot slower.” These professional foci show differences between the objectives of personal trainers.

\section{Motivation}

A key characteristic for all personal trainers was motivation which often took on the guise of 'compliance.' Trainers mentioned learning how a client can be motivated is needed for any success. Personal trainers pointed to the differences among clients in their acceptance of motivation. Maguire (2001) is an example of a personal trainer's need to be flexible to the clients demands and wants. Unlike television programs, screaming like a "drill sergeant” was not one of the techniques the particular respondents in the research identified with. One tactic is to function as the "professional cheerleader" to stimulate clients when working out and to continually work on an exercise regimen. Paul shared his technique, the following way: 
I usually start off and progress into an intensity that I like. I don't want to start off to fast and to quick and to hard because then they are going to be tired and usually not going to be able to finish the workout so I usually start off slow and easing into it and as were going along you know, 'really good job your doing great here just keep it up.' And then after we really start to get after it I might start clapping just raise my voice a little bit start to clap. A little bit more noi... The louder you get the more that they kind of sense that it's time to get after it. You know, they kind of change the mood a little bit and they can realize from that well 'I've got 30 seconds left let me really get after it here.' If you're there in ear....ifyou're in their ear clapping like 'let's go, let's go, let's go, keep climbing. Let's go come on keep it up,' then more likely they are going to be like 'alright' and they start to get after it. We let them rest and get recovered then get right back into it, ease up into that point again.

During the interview he actually clapped his hands together and bent over in his chair, giving a sense of physical presence and motivation, while he was describing the clapping and "let's go...." motivational talk. Paul then takes the interpretative side of his job when he describes the 'alright' notion of the client and their intensity of exercising. Not only does this describe how he promotes personal training but also the physical exercising practice and techniques that are used to change the client's body. A similar formatting of practice was given by Matthew, claiming “motivation...that's getting them to push themselves to the limit." While motivation takes place there is a "fine line between a great workout and overtraining." Timothy mentioned "biofeedback,” which represents the technical evaluation, and the "talking” or social evaluation, techniques used to keep a client working in a productive manner. Later in my interview Timothy alludes to the importance of motivation in order to "get them to believe in you." This belief and knowledge relates motivation, evaluations, and teaching together with the business aspect of personal training.

For the client to "believe in you" and to "believe in themselves" was a reoccurring theme throughout the interview. In the following Zack shares how his goal is "to help you believe in 
yourself because I do.” He even shared his technique of nutritional foundations and follow through from the client, which is an extrinsic control on the intrinsic value of control,

If you write down what you are eating and you show it to your personal trainer, you know what I mean. It's not like I'm gonna be pissed. It just makes you more aware like, you know what I mean, of a desert or something that you eat. So you're like working hard and you're like 'I don't want to see this.' So I'm not gonna eat it. At the same time I have clients who say 'I don't want to eat this stuff.' They keep their workouts in the book, so it works in itself.

Not only does the client have to be "self-motivated" but they have to believe that subjecting themselves to physical stresses, "pain” is working for them. Personal trainers help reassure them of success by constant evaluations and motivation (the technical and soft evaluations previously mentioned). The trainers commented on the initial drive that clients have to posses just to get to the gym. David described it best when he said, "you can be there to encourage them while they're there but you can't really encourage them to actually get to the establishment.” Another aspect of this "internal motivation” of clients was mentioned by Sarah when she was describing how “you can’t motivate a person” in regards to them not continuing to train with the trainer or even working out because it is their lifestyle.

Until they desire it in their heart, then they're not going to do anything about it. So really a person has to want to change. They have to want a better life. They have to want better health.

Desire and acknowledgement or demands for services by the client are what provide the "personal fitness trainer" an occupation. But the reaffirming and the need for feedback and cyclic evaluations, both technical and social, have to be in place to actually practice on the body.

An interesting response in relation to motivation was given by Timothy when asked I asked about the meaning behind motivation; he replied with the following:

I mean motivation... I think there is a lot of uh, I'm kind of saying this carefully. Cause I think it's kind of ah, I don't like sometimes how we are 
perceived as just motivators...So I don't consider myself just a motivator. You know, because I'm a professional giving professional information to reach a certain area. Now as far as being motivated I think it's, first finding some landmarks and basically setting goals and trying to set some specific goals so that they can be motivated by seeing progress. Also, of course having a good relationship with that client to where you know, finding out what their motivating factors are.

This aspect of “professional” was later referred to as his education (Masters Degree in Exercise Physiology) and his experience (15 years) in the field of rehabilitation and fitness. His narrative about issues of finding out how a client is motivated focused on his professional status as a personal fitness trainer.

$\underline{\text { Business }}$

Clientele and client success interact as the basis of revenue and means by which the personal trainers get monetary payment. The fitness industry - business- is a reaffirming the legitimization path from a proto-professional to an allied health professional. There was variation in the services of trainers in technical evaluations (more "scientific" versus "basic" assessments) as well as business (financial, paperwork, etc.). Both Zack and Matthew were “independent contractors” who worked at a nationally recognized franchise. Bradley, Sarah, and Timothy all practiced in local wellness and physical therapy fitness centers (incorporating in house sub-professions such as physical therapy and wellness coaching). Andrew owned two local gyms and concentrated his efforts on nutrition for the masses. David was a formerly employed by a local gym owner. Carly worked in a local gym as well as her athletic training occupation at a higher educational institution. Paul worked at a regionally recognized franchise which incorporated personal training for all clients. Both Jane and John worked in a recreational center for college age students. Finally, Kathleen taught personal training at the college level 
and worked at a local fitness center, respectively. While there was a range in their locations, there were similarities when it came to business.

The "independent contracting” trainers elaborated on the development of their own "LLCs" in order to promote their services. Working at a nationally known franchise brought members to the gym but did not guarantee cliental. When questioned about his work hours beginning at 4AM Zack mentioned, "I run my own personal training business that I run out of this place.” Even though Timothy directs the fitness part of the multi-medical facility his personal training business is structured around the clients’ personal lives, “My hours are generally set by the client.” Many of the respondents commented working around the client's schedules and which time of day works best for them to receive services. Timothy explained his work schedules the following way, "Now, I try to accommodate clients because I generally know that, you know, their busy lifestyles. You know, so they have, you know, their work schedules. They have their 9-5 so you know, I know that if I'm going to have a good clientele I have to accommodate, I have to make certain accommodations to work around their work schedules because they're ultimately paying me so they have to work in order for me to receive my income so I, uh, it’s something that I have to accommodate.” These respondents (along with others such as Sarah) referred to "word of mouth" as their biggest marketing tool for potential clients. She said, "I typically work on a referral basis. And if you look at marketing, word of mouth is by far your best form of advertisement.”

Other forms of marketing and business promotion for Zack and Matthew included websites, business cards, and an "active presence” in the gym. The active presence of Zack relates to his education as a personal trainer and is a certified athletic trainer and gives advice to members of the gym "to a certain degree" if they have questions, in order to attract clients. 
Matthew also uses his educational achievements as marketing tools for his business relating to him being a Strength Coach Certified and his nutritional certification. These two respondents participating in free agency varied among the others because they had to actively engage outside sources for marketing their business. Matthew describes his advertising means other than wordof-mouth, "I have tee-shirts that have the website on it. I have a website. I brochures, business cards, and ah, I use Facebook, MySpace, with my website link to it. And umm, International Bodybuilding Association has umm my website linked to their site.”

The in-house trainers (those who work in facilities which incorporate more than just the personal training practices, such as physical therapy, rehabilitation, etc.) specifically Bradley, Sarah, and Timothy do not do their own marketing to the public because the "facility is known" for its programs. The in-house services of physical therapist also provide "referrals" to the personal trainers for future clients.

Referrals were typically negotiated for the fitness clients by doctors who were instructing their patients to get healthy through physical exercise. Sarah and Zack mentioned the connection that could provide personal trainers with a referral program from a doctor to increase business for personal trainers. This would increase the jurisdictional responsibilities for the protoprofession, possibly increasing the occupational development and legitimization. Sarah who was also a hospital based nurse, reported about other professional referrals from pharmacists and doctors. These connections between occupational services and business concepts vary from the other personal trainers in their interviews.

Among the other trainers, their jobs were located at specialized facilities/gyms where there were either specific techniques used, cliental permitted, and services rendered. The specific techniques used in program design were implemented by Paul because of the facility that 
he worked at. Everything he did was pre-determined and already "developed" by the creator of the specific facility. David worked in a specialized niche, “women’s only gym,” which was owned by a local entrepreneur. The personal trainers who worked at the fitness facility of a higher educational institution were not paid, but received educational "internship hours" for their work completed with their clients, who ranged from students to paying members of the community who wanted to join the gym. These personal training services for members from the fitness facility were provided as part of their fees. Jane mentioned the difference of the free services and how people "just take advantage of that" and sometimes never show up for their scheduled appointments." John agreed it allowed clients "to just go online and sign up for another one" even if they did not make the first appointments. While there are free services provided by these trainers, Kathleen, who trains the "student personal trainers," shares knowledge and respect to a business protocol for those studying personal training.

A few trainers talked about client management, dealing with multiple clients, "single sessions," "package sessions,” and nutritional guidance. Matthew alluded to his goal of maintaining his cliental while other respondents advocated educating the clients so that they can exercise on their own. Most trainers sold "package sessions," multiple workout sessions for a set price, to the client or a small group of clients (a pair of clients). After non-complacency of the clients the respondents mentioned different business avenues to socially evaluate the client's needs (i.e.: if they were sick and missed a session, or if the client is just not interested). If no communication is made on behalf of the client to the personal trainer in response to "check-ups" then the services of the personal trainer are dropped for the client or the client is charged a "penalty fee” for not showing up or attempting to cancel/reschedule the appointment. Sarah 
shares an interesting case in the following statement regarding clients who do not comply with the personal trainer services:

You'll see these like repeat offenders at different facilities. They'll try these different trainers for a few weeks or a few months and then they'll switch to someone else. It's because they want results and aren't willing to work for them. So I do as much as I can but you know, if huh, if someone no shows me, and doesn't call then I charge them for the session. Umm and, if ah, if it keeps on happening then I just call them and say 'Hey, you know, umm I'm not sure what's going on you're more than welcome to talk to me about it.' And if I don't get a call back then I just say, 'Thank you for your time. It was a pleasure meeting you but I won't be able to work with you anymore.’

These business protocols are also controlled with proper “paperwork” such as keeping track of medical release forms, health histories, and other information regarding clients' needs. This “service oriented business” (Carly and in Maguire, 2001) helps researchers and applied professionals relate how the client is paying for the personal trainers' esoteric knowledge and application in order to transform their [the client's] body.

\section{Part II: Inclusion of Personal Trainers in the Professional Landscape}

The rationalization of the personal trainer occupation is the ability of personal trainers to transform client’s into healthy “good citizens” (Crawford, 1980) relative to their embodied selves. Throughout this next section, literature and research data intertwine to show the mapping of the professional landscape of the human body, combining with the sociological implication of health (meaning a useful body, good citizen, and control). There are different professions and sub-professions with connecting links that all have to deal with the physical body, and affect the actions of personal trainers clients.

The dealings among different professions show the contested field of personal training in many different aspects. The education and experience varies among the trainers, and certifications show the difference in occupational identity among them. Different methods of 
evaluations and techniques used during training are reflected in "program design" or "prescription” which exhibits the professional power of the personal trainer related to their field and jurisdiction.

These boundaries are challenged among different trainers in relation to the "networks" of organizations which bring into play concerns with "accreditation" and recognition of the different personal trainer associations. These different perceptions of the "professional" organizations for personal trainers had some relation to the descriptions from each respondent and some organizations carry more prestige than others. For example, the National Medicine Sport College (NMSC) was mentioned as the organization that sets boundaries and rules for testing the clients. The NMSC with the Strength Organization and the National Exercise Council were among the top organizations, and to a certain extent, there is regard for authority in the field for trainers affiliate with those groups.

\section{Micro Structure Mapping}

Breaking down the organizational identity of the respondents helps map the micro landscape of personal trainers. In response to working with clients and the purpose of being a personal trainer Zack said the following, “I mean it’s not like I'm a student here in law school... [changing somebody's body] that's what I'm here for.” Trainers talk about the difference between who know what they are doing and someone who just works at the gym. David's profile places him as a student in Information Technology (IT) who works as a "trainer" at a local gym. Other themes found were the following: concern with having "certificates," certification organizations, and experience partnered with education. Sarah shared a concern as whether there is a difference between an exercise physiologist and a personal trainer,

Absolutely! An exercise physiologist is someone who has an exercise physiology degree. And a personal trainer, like we've already talked 
about, is, you know, can be a whole wide range of things. They can just not have an education and be 18 years old. Have a CPR, umm certification. Send 50 bucks in, answer a few questions, and you're a certified trainer...I'm an exercise physiologist.

Using the argot of trainers (Corbin \& Strauss, 2008) helps us define how they are identified as well. My trainers interviewed varied in age, experience or job history, “professionalism,” and nature of personal training. Each trainer had a different certification background and educational experience. There is a broad spectrum how the professionals among the group acquired knowledge. David just took a “personal training course” from a nationally known gym franchise which awarded him a "certificate” and now works with for a gym owner. Kathleen, who has worked in the field of fitness and personal training for 20 plus years, is certified by National Exercise Council and actually teaches personal training courses at a higher educational university. Paul, Timothy, Matthew, and Carly are all Strength Coach Certified personal trainers. Jane and Sarah both had other certifications of personal training from weekend courses and exams they took with two different certification organizations. David, Zack, John, and Andrew did not have any affiliations to personal training organizations. Zack and other trainers actually are qualified in other sub-professions such as nursing and athletic training, which will be discussed more in the ensuing chapter.

The trainers commented on the ability to gain entry into the "personal training field” with a certificate. In the following statement, Carly ties obtaining a certificate to being easily accessible and attained versus the certification process which takes education and a degree of commitment, "You know the big difference between the certification and the certificate is actually being educated as opposed to taking simply the online class.” There are no legal ramifications for personal trainers to be certified or have a certificate to perform their duties as of now, but certain practices of health workers might ask for particular experience and education, 
such as at Paul's place of employment, which required most of their employees to have at least a “junior standing in the field of an exercise physiology type of degree.” Even with that experience and graduate work in Athletic Coaching, Paul made the following observation about being a certified Strength Coach,

Umm the certification really looks good and the knowledge you get from studying for the certification can really help you out later on... and certifications... let others know you know what you are talking about.

The aspect of studying for a test is still apparent when it comes to all of the certifications mentioned.

The facilities (usually gyms designated for athletic development) concentrating on athletic strength and training employ trainers with different types of certification. This organization concentrates on research and development with conditioning and strength/fitness. Paul's member affiliation requires “paid yearly memberships which include journals.” With that membership they get discounted prices on exams and materials such as continuing education units (CEUs). Their main certification provides conditioning and strength knowledge to members but they also offer a personal trainer certification as well. Matthew who also has this organization affiliation commented on another certification agency, National Exercise Council with the following statement,

A typical personal trainer could be somebody that just has workout experience in a gym and they go study for the National Exercise Council test, pay 250 bucks, pass the test and not really know that much more than a regular person when they're out instructing.

The contradictions and bias from different organizations is apparent in the beginning stages of this professions’ development.

Kathleen, who provided very detailed information regarding the certification process for National Exercise Council was very adamant about the procedures, policies, continuing 
education and development of their organization, “They are called America’s watchdog because you can read in Parade magazine, or quotes in magazines. They are usually from the National Exercise Council.” This shows the publicity of their organization on reporting fitness, health, and wellness information with the consumers, which is another step in providing services to the customers and people who are longing for the knowledge of professionals who can share that information in exchange of monetary means.

According to the trainers, associations have different requirements and membership guidelines. Sarah expresses her concern in another manner with this statement of a "good" personal trainer compared to others related to certifications:

Now here's the stipulation with personal training that I have a really big problem with. To be a personal trainer technically you have to be 18 years old, hold a valid CPR certification, and take a test that "certifies" you as a personal trainer. Now there's a lot of hokey organizations out there on the internet that you give them $\$ 50$ and you are a certified personal trainer. Let me tell you what. If an 18 year old goes out there and does that they're gonna hurt someone. They're gonna hurt someone very badly. So, here I am with two degrees, three certifications, 5 years of experience and I consider myself a really good trainer.

For Timothy, "There are different organizations. There are a lot of organizations out there now.

So umm. Typically you need, you need to be you want to be umm, certified by more of an accredited type of organizations.” Kathleen focuses the background of accreditation of personal trainer organizations here,

With the NEC certification you had to study probably six months and do about 100 hours in a fitness center before you were even ready to take the exam. And then other certifying agencies you would go for one day for about four hours, take the test, and get a piece of paper that said you were certified. So umm, there is the national, it's called the NOCA. National Organizational Certifying Agency, out of DC. And they actually make you third party accredited, which means you give them your material, you tell them what someone else, a third party has to make up your tests. So I don't know what's on the test, I can't teach them and say this will be on the test because I don't know. And that's why it's third party accredited. 
This seems to be an attempt of the organization to show its legitimization for professional work by “...tracing them to major cultural values.” (Abbott, 1988) These values place emphasis on structure, education, and legitimization.

Macro Structure Mapping

In the Abbott work, The System of Professions (1988), he examined highly structured professions in the legal and medical fields that controlled expert knowledge. The transfer of power in the medical field can be seen through the development of the specialized areas of medicine (i.e.: optometrist, urologist, physical therapist, and dentist). Subsequently, there is a larger structure in which the personal trainer fits into the medical professional field. Using Abbott's theory, inter-professional differentiation, the diagram below is this researchers' attempt to map the social landscape of the body, including the placement of the "personal trainer."

Interacting Systems of Medical Professions and Sub-Professions

\begin{tabular}{|c|c|c|}
\hline $\begin{array}{c}\text { LEGITIMIZED } \\
\text { PROFESSION } \\
\text { MEDICAL DOCTORS }\end{array}$ & $\begin{array}{c}\text { LEGITIMIZED } \\
\text { SUB-PROFESSIONS } \\
\text { "Allied Health Professionals" }\end{array}$ & $\begin{array}{c}\text { "FITNESS } \\
\text { WORKER" } \\
\text { "PSEUDO AND WOULD-BE } \\
\text { PROFESSIONS" (Abbott, } \\
\text { 1988) }\end{array}$ \\
\hline & & \\
\hline Physician & $\begin{array}{c}\text { Certified Athletic Trainer } \\
\text { (ATC) }\end{array}$ & "Certified Personal Trainer" \\
\hline Dentist & Certified Strength Coach & $\begin{array}{c}\text { Individual Certified in } \\
\text { Nutrition }\end{array}$ \\
\hline Neurologist & $\begin{array}{c}\text { Emergency Medical } \\
\text { Technician }\end{array}$ & Trainer \\
\hline Obstetrician Gynecologist & Exercise Physiologist & $\begin{array}{c}\text { Self-Identified Persal } \\
\end{array}$ \\
\hline Optometrist & Dietician & \\
\hline Osteopathic & Nutritionist & \\
\hline Pediatric & Pharmacist & \\
\hline Physical Therapist & Nurse & \\
\hline Urologist & Physicians Assistant & \\
\hline Chiropractor & X-ray Technician & \\
\hline & Laboratory Technician & \\
\hline
\end{tabular}


This macro landscape of the medical professions, previous table, goes hand-in-hand with the description given by Abbott regarding the control of work and professions emerging in the medical landscape, "This internal subordination of routine work is a characteristic strategy of professions claiming more jurisdiction than they can effectively serve, American medicine being the best example.” (p. 25)

Learning how to properly manage the body as fit for action comes from the knowledge of personal training. The links to medicine can be seen through the perspectives of the fitness trainers. Initially, the personal trainer has his/her client examined by a physician (general practitioner of medicine) for medical approval and referral to participate in physical activity if there are risk factors. Bradley shared this piece of information,

I'll do like an interview and I'll have them fill out like a medical history form so it tells me if they have two or more risk factors, two or three. It tells me that certain factors need a doctor referral.

Other jurisdictional boundaries from the personal trainers with other medical professions and sub-professions can be seen in the referral process regarding the following scenarios.

Carly engages in the referral process if there are issues; she would use someone "that may be within my network of personal trainers or medical field, say 'you'll do better with a physical therapist with your injury.'” Or if specific dietary needs seem appropriate she would recommend "basic" nutritional advice for her clients unless if there was a serious issue regarding nutrition. In giving advice for higher risk nutritional needs Carly said, “No I don’t really think that that's my job qualifications. If it's so sever then I would need to say, 'you need to see a dietician.' Or maybe look into that." 
Timothy shed light on the intriguing dilemma personal trainers see every day in the workplace referring to people coming into the facilities, without prior "knowledge" of the body, expecting to start a workout program on their own,

That's another thing to a lot of people just come in and ah, they're not doing things properly... I catch a lot of people, a lot of amateurs coming in off the street and just coming into the gym. 'Doctor said I need to lose weight' and they just pound it.

He is referring to the knowledge needed to help people who were told to deal with fitness and health problems by medical professional; e.g., without the correct manner of 'losing weight,' and the individual at risk is “doing more harm than good” according to Matthew.

Many younger personal trainers delved into the scenarios such as a client just comes into the gym as a part of an exercise program because they want to get into shape. A situation where the personal trainer comes across a patron of the fitness center, who was told by their doctor, they need to lose weight, was disturbing to some more experienced professionals in the field. These professionals were concerned about the wellbeing of the individuals who were exercising under no form of management or advisory roles. Timothy shared the impact working without personal trainers might have on someone's outcomes whereas if they paid for his knowledge they would be put in a program to achieve maximum potential,

So it's always amazes me when you talk to people and they have a certain goal and they are just training, basically sometimes counterproductive or sometimes not even close to the level that they need to be training to reach their goal. So the person who is actually training with me is going to maximize their time in the gym, definitely going to maximize their time at the gym, at the gym, and do it in a safe manner.

Sarah voiced the benefits of working in a multi-disciplinary facility,

Doctors typically don't outsource to personal trainers to nutritionists, okay, because there is this barrier here. That's the really neat thing about our facility here at Ultimate Fitness, is we have Dr. Fixmeup. Then we have our physical therapy department. Then we have our personal trainers 
and our fitness department. So we have this whole circle of people communicating with each other. Same patient visits each one.

Personal training can provide an individual a significant resource when it comes to protecting a client's health and body.

A minor theme found through the coding process when it comes to the individual's fitness knowledge (creating the need for the personal trainer). "But the general public doesn't have as good of an education on fitness as they should for the most part.” Matthew commented. He clearly states the purposeful need for personal trainers in the medial landscape, in regards to the useful and usable knowledge, with the following:

So basically if someone goes to a trainer sometimes they're paying for the educational purposes as far as doing things with the correct form.

These "forms" are not just lifting techniques but also cardiovascular related exercises, motivational techniques, and physiological responses to demanding activity which change bodies and identities. The knowledge to heal bodies has had its professional structure more than a century, now there is growth of the field in changing the bodies, and bodies are kept fit before the healing is required.

How trainers deal with fitness and their jurisdiction over it, and how they deal with it reflects control and jurisdiction. Controversy lies within the education of the personal trainers. As mentioned previously the “certificate versus certification-certified personal trainer” and higher education are among the controversial issues of the trainers. The trainers themselves express contradicting viewpoints of their own field of personal training. Carly sums this up: “...I actually have a degree in what I do as opposed to most personal trainers.” This simple statement opens the doors, the stability of “personal trainers," in the medical landscape. Like Carly, Matthew has earned educational degrees, yet challenges the aforementioned jurisdictional 
boundaries of nutrition and personal training with his comment, "Well. I'm not only a personal trainer. I'm also an exercise physiologist and nutritionist.” This knowledge is personalistic based on a Master's in Exercise Physiology along with Bachelor's degrees the preceding subject and Nutrition. Sarah and Timothy also identified as exercise physiologist who use their knowledge in the personal training field. Education, according to a portion of the personal trainers plays an intricate role in growing disciplined knowledge, but still is challenged by the along with the hands on experience of other "successful" personal trainers. 


\section{DISCUSSION}

Knowledge of Body Changing

Personal trainers are a growing occupation in part because there is a fitness and health market for them to sell the idea/product of improving or gaining desirable muscles and bodies. Viewed from a macro-systems perspective, personal trainers' accounts show how they not only marketing their "products" through "changing the body of clients," but also seem to be gaining a special niche in fitness and health in relation to other sub-professional services. As mentioned previously, trainers like Carly, Timothy, Zack, and Sarah combined into their practices their experiences in aquatics rehabilitation, athletic training, and nursing. Their control over fitness practices not only help them with their clients but helps their skill of and authority in athlete training, post physical therapy patients, as well as diabetic clients with high risk factors, who are all attempting to change their bodies as well. Sarah subtly boasted about her knowledge in nutrition, “I’m kind of the expert here (facility) on nutrition.” She even claimed the other personal trainers who work with her would say so and come to her on nutrition advice which gives her another avenue of control of the product. The medical profession already has professionals and allied health professionals who are working with athletes; the aged; injured populations; and other chronically sick people. This research of the personal fitness trainer shows how this proto-professional occupation is developing in an emerging market because of the willingness of people to pay (or to be insured) for the physical needs.

As an occupation, the work of personal fitness trainers is also highly contested. In review, some of the micro level discrepancies are pre-exercise testing, measurements, continuing education, as well as educating clients to prepare them for healthy lifestyles without the professional services of the personal trainer. Trainers expressed concerns about different associational affiliations among fitness workers and importantly, the responsibilities or 
jurisdictional boundaries claimed among trainers in relation to knowledge and education this proto-profession depends on. Likewise, the referral process varied widely depending on their practice facility and its overall professionalization.

The control and authority of in-house referrals from doctors or physical therapist can transfer a client directly to a personal trainer. Beginning to work with a client typically meant that if a client did not pass a legitimate health questionnaire (PAR-Q), then he or she would have to be referred back to a physician regarding the status of their health prior to exercising with the personal trainer. Aligning this research with Abbott's work on the medical and legal professions allows a better understanding of the current state of the personal trainers.

\section{Legitimating through Business}

From my data about personal trainers (the actions they take to practice, how or the methods they use to practice, and when they practice), the personal trainer is not a full professional, compared to the general practitioner of medicine, but rather fitness trainers are a growing quasi-profession in the organizational landscape.

With regard to the practical, common-sense knowledge shared among personal trainers, how they acquire what they know and the practical common-sense understanding they can use with their clients show several different paths to acquiring their knowledge (i.e. schooling, experience, and internet “testing online”). Some personal trainer associations and some, but not all affiliated fitness facilities do focus on practical knowledge by requiring a degree program from a college/university for their fitness staff. Some colleges offer degrees with heavy investments in internship-like personal training education. Kathleen is the teacher providing instruction used by personal trainers. Personal trainers share common training programs, and have gained a wide range of procedures and information, but with today's rapidly changing and 
improving channels for exchange of information, they are not the only ones with a special claims using fitness skills (a key factor in providing the jurisdictional boundaries with professional knowledge). But with uncertain skills, those working in personal trainer jobs may "take an online test," and claim to be certified and enter the occupational market the same as the master instructor, and so the outcome with the clients might not be remarkably different. Results are what need to be measured to determine what separates trainers in their occupational endeavors; namely, their success. The claim to having a superior education, "proper methods" of training, and experience are what is challenged by the growth of the occupation.

The "diagnosis" or fitness assessment is a key consideration identifying the personal trainer as a professional worker. Personal trainers reported they are not allowed to "diagnose injuries or conditions” for a client. Kathleen puts it:

When you have a patient that means they have been diagnosed and prescribed something. And we don't do prescription and we don't diagnose anything. Although people will ask you all the time you know, 'This hurts, what should I do?' And you have to be real careful. That's a fine line that you don't cross.

Trainers are careful about how they handle pre-testing "medical forms," both to protect the client and likewise themselves, legally. If a medical issue arises during the "medical history" process then the client is referred back to a physician for examination before work fitness trainer can continue to work. Zack discussed the referral process in relation to other para-professional practitioners. Zack is not a physical therapist but is a para-professional (certified athletic trainer) and a "personal trainer," who routinely works with clients that have just finished physical therapy (a unified profession dealing with injury rehabilitation).

Along with the liability tied to diagnose injury or sickness, personal trainers who talked about their experiences or lack thereof concerning nutrition as a factor touching jurisdictional 
boundaries and referrals. Andrew (who is not a certified personal trainer but has 20 years of experience) shared how he attended costly seminars and has had repeated meetings with a physical therapist and nutritionist, who gave him "permission” to use the nutrition techniques, methods, and knowledge to change bodies of clients. Sarah also learned a good deal about nutrition and nutritional education when she took classes and then passed a test for nutritional counseling from her affiliated fitness organization. When questioned about work with diabetics or clients with allergic reactions to gluten, trainers mentioned referring clients to a nutritionist (another sub-profession of the medical field). There was some discussion about "prescription" but trainers avoid any notion of prescription because it refers to medical doctors prescribing medications, and "personal trainers should only provide exercise programs not exercise prescriptions” (data given by Kathleen who teaches). Role definition is an influential factor in the professionalization of any occupational group.

An extra-mural aspect of recognition as a proto-professional is to be included into "billing for service" to medical insurance or health companies. Becoming a "provider" in the scheme of paid fee-for-service medical providers, secures an economic reality for services. This is a strong drive for a "fee for service" relationship within the fitness and wellness industry. The legal and economic function sets up a charge for the personal trainers, along with other medical professionals. There is not only "internal motivation," as noted by Sarah, but also an external motivation in terms of a financial reward when insurance companies pay for a gym membership and personal training services, and also for the client/customers there are lower costs affiliated with the health insurance. While personal fitness training is still new in the medical and health professions, some personal trainers hint at the notion of the impact it can play through health and wellness of the clients. Sarah explains personal training as an "extraordinary expense" so when 
individuals start to go on a budget, people "first cut back on things that are frivolous." Sarah is passionate and she sees her services as the following, "I'm like this is insurance for your health." Paul acknowledged how important the clients' employers are in gaining participation in the fitness/medical industry.

Umm... health and wellness is a field that a lot of corporations use. Umm as far as like their health and wellness umm programs they like to have their employees... healthy and fit that way their insurance isn't extremely high. Because if you've got a bunch of smoking fat people employed at your business umm chances are you're gonna have to pay a lot more in health insurance. So these wellness programs are popping up a lot more based upon those preventative measures that people are starting to take.

There is a legitimate connection between business (insurance) and the proto-profession like personal training. The reasoning for medical insurance companies to pay for the services of personal trainers is just as they do for chiropractors, doctors, and surgeons.

Creating a revenue stream in training is not difficult. Andrew has been using the entrepreneurial idea of opening two gyms for the past 15 years of his career. Sarah targets clients who specifically want nutrition advice, Zack uses his athletic training knowledge to build muscle for clients who have specific physical limitations, and Carly focuses her interest and knowledge on the geriatric population by keeping them engaged as influential social actors in the world. The clients/consumers who will pay for these services are from a broad spectrum, from the injured coal miner who still needs to change the body even after the physical therapist has rehabilitated the injury, to the woman who wants to lose 10 pounds to fit in her wedding dress, and then to the male body builder who wants to cosmetically adjust his body in order to create a new identity of strength and muscular development. Each customer brings income for personal trainers, but their business depends on "referrals" within the fitness industry to market the product to more consumers/customers. 
Personal fitness trainers and their organizations have to prove successful in order to partner with the health insurance industry to gain that business and have an economic impact. This need also feeds the motive to create the personal training as a para-profession. Not only must the personal trainer show the knowledge and skill of getting the embodied self into shape to perform, but also in the future, will most likely need to be able to show their effectiveness. This need almost assures an increased pressure to move toward licensure, diplomas, or recognition from outside - professional certification organizations - who can claim "monopoly" of this work as the rational process for health to the public.

Attempts to "monopolize" practice are a part of the development currently facing individuals as "personal fitness trainers," and there are mixed feelings about what a "personal trainer" does. My respondents had strongly stated opinions about members of the "personal trainer" occupation:

"Most trainers around here think they're trainers because they read Muscle and Fitness Magazine, workout, and take steroids."

"A typical personal trainer could be somebody that just has workout experience in a gym and they go study for the National Exercise Council test, pay 250 bucks, pass the test and not really know that much more than a regular person when they're out instructing. And some of those trainers can be phenomenal. And some exercise physiologists don't know how to work out because all they have is book smarts."

"Well,...you need to have some kind of experience because if you are gonna be telling people how to work out you need to know what you're talking about. You can't just go and say 'Okay well you know, just go over here and do this' because then you're just going to perpetuate the myths that are out there. But you don't necessarily have to have that from a school or anything. You can you can receive that from just like a tutor or mentorship or something from somebody that's working above you."

"It's all the same. It's all the same. As long as you are a personal trainer it's all the same. You can get certified by the International and Medical Sports Association and it is the same thing as strength and conditioning. At least in the insurance's eyes that's all that matters.... That's a good one to have just to kind of pat your resume. They, anything that can be used to 
pat, anything that allows you to do anything more legally. Certified strength and condition, nutritionist, certified body builder, it all, it allows you to pat your resume to someone who doesn't really know about the differences."

The last opinion outlined how legal issues are used to legitimize the business and consumer services and quest for the product. The degree of influence on the consumer comes not only from the trainer but also the marketing and development of the profession as a whole. Abbott (1988) makes the point that, "Diversity would disappear with time, as groups gradually acquired all the marks of true professions.” (p. 4) Carly gave some insight on her predictions of the legitimization of personal trainers related to certifications in the following statement,

Well there are certifications and there are certificates. I think all of the certifications are eventually going to be all boiled down to being accepted as one unit. Now the certificate is someone who just gets online, takes a test, and then they get a piece of paper saying they passed the test. And they get everyone, no matter certificate or the certification, can say that they are a certified personal trainer.

Creating the new identity of the personal trainer for the public lay people (consumers), could and can allow group members the ability "to practice” on bodies.

$\underline{\text { Inter-Professional Communication and Context }}$

Abbott (1988) noted “People don’t want to call automobile repair a profession because they don’t want to accord it that dignity.” (p. 8) If one thinks about the trainers' situation, personal trainers could be regarded as just body repair workers. In this case, however, the personal fitness trainer is working on the same human body as the medical profession. The muscle and fitness focus, if structured and developed correctly provides an opening for trainers into para-professional jobs in the medical field, because of the growing intellectual discipline it takes not only to work on the body but to work with the clients. Fitness work is sometimes as 
engaged in an "emotional labor" or a psychological effect as a physical one, like a cheerleader, bartender, motivator, coach, etc.

Interviewed personal trainers typically believe they need to develop jurisdictional boundaries with the other allied health professions. Instead of making the trainer an easily accessible occupation there are steps that certifying organizations can take to become more expert, notably more profession-like as an occupation. Certainly, more carefully rationalized selection to membership based on acknowledged bodies of knowledge and practical competencies would facilitate the institutionalization of legitimate boundaries for their ability to improve or build fitness. Ultimately, if consumers (those paying for the services) understood the nature and types of services leading to fitness outcomes, personal trainers could gain the practical competencies and secure occupational control needed for independence, thus promoting income and occupational status. That is to say, so long as the fitness trainers' job is a highly contested terrain of knowledge, skills, and earnings, its recognition as a successful allied-health profession will be disputed and weak. In order to change, personal fitness trainer associations need to inform clients that the organization presents the best service and success for their own fitness. 


\section{FUTURE RESEARCH}

\section{Quantitative/Qualitative Analysis}

My research signaled a personal beginning for me to understand the development of personal trainers, who they are, what they do, and how they fit within the professional health and fitness landscape. There an array of associational affiliations available to personal trainers, various methods of how to become a trainer and a whole host of fitness problems or health conditions that brings the client/customer to the personal trainer. Their occupational experience is comparatively unique from one another, and their own self-conception is likely to express an uncommonly high self-regard about their competency as a trainer while assessing flawed performances by so many others who work in and at the occupation (Appendix B - Extended Profiles). For an occupation that is growing rapidly and so to speak, trying to break into the professional landscape, my study suggests there is as much division as there is common ground. This finding alone - the contested nature of the occupation - warrants further study. My work was intended to help understand a changing occupation, and make suggestions based on evidence and bring awareness to its’ condition.

Future studies should include quantitative assessment of the financial impact personal trainers could and can have in the fitness and health community. There needs to be a study of years of experience compared to a perceived level of expertise and at least, the training and level of knowledge held by each respondent. Other studies can focus on associational factors and behaviors to understand the differences between these proto-professional/allied-health groups.

\section{Perspectives of Legal Issues and Business}

The research about professions and professional development - organizational structure, social functioning - point in the direction of understanding where the occupation or professional is going, how other actors perceive them, and where they get along or rely on those actors. 
Abbott's work entertains a set of questions about how professions develop, inter-professional relations, and the content or manner of the activity in which professional perform. Essential to this literature on professions is the concept of "regulated jurisdiction" which deals with the nature and types of specifically expert-based work taking place and examines how such experts, that is how professionals control their knowledge and legitimize their practices (1988). In my case study, the personal trainers are claiming knowledge and understanding of a client's fitness.

While all the respondents might be able to claim they have the ability "prescribe" programs for successful outcomes for a fee, the trainers had remarkably different ways to do their jobs, both technically and in regard to the aims of their services. Experience and commonsense approaches were questioned by trainers who had higher educational degrees in kinesiology and exercise physiology, and vice-versa. Those trainers who are driven mainly by economic profitability or income concerns were quick to question the relevance of academic degrees for fitness goals. As consumers we can see a concern with fitness occurring daily, with backing of insurance groups for employees to attend a gym or work with personal trainers. This industry will continue to grow because people will pay for the services personal trainers can provide, as mentor, as coach, as motivator, or therapist, and teacher.

Future research on personal fitness trainers, and its evolution into one of a growing body of para-professions should be viewed in a context of organizations and stratification. Acknowledging the "internal hierarchy" among professions (Collins, 1975) personal trainers can place their occupations into the professional medical or allied health landscape. Collins also notes how collegial groups are empowered through legislative action formalized by licensing and requirements, and that further legitimation/authority is gained with collegial praise in judging 
another professional's skills, actions, and success, and by recommending them to other members of the group.

Sarah shared how she refers clients to other personal trainers if the client is looking for some different style of transformation,

So I would say I'm kind of the expert here on nutrition. Now, if I had a football player come to me and say, 'hey, I need a program to be a linebacker.' I would say 'hey, I can work on strength things but if you really want something specific then I would suggest so-and-so'... So you know, we work together here. We all have our different specialties.

Becoming professionals include an ability to provide results through the services, transforming the body, and also having the laymen or clients value the task. Zach mentioned this in the beginning of his interview when questioned about clients coming back, "They want to see results.” Personal trainers must provide successes to clients and to other members of the consumer culture who want to change themselves in order to have a highly desired service.

There was an apparent divide in the personal trainer respondents when it comes to "keeping the clients coming back for more," according to Sarah. Jane mentions educating the clients on how to take care of their own identities and just checking in on them monthly. These personal trainers both, according to Collins, are the "pillars of strength in the storm" but the continuation of the client coming back for guidance and strength changes among the personal trainers. Matthew, on the other hand mentioned at the beginning of his career he would have people sign one year contracts for personal training, but now, "I've choose to kind of do away with my VIP program and make more per hour.” There is an emergency of identity with the clients but continuing the business or providing expert knowledge changes through the respondents in this research. Andrew, who concentrated mostly on nutrition, shared the following: 
Dieting, I would like all of them to come back to me because dieting is, you just can't teach somebody everything in a session. It's a continuing education type program. And my most successful clients are the ones who come to me. Ah, no matter how good a program is you can't give all the knowledge to people in a week. So if someone only comes a couple weeks to meet with you, they only got a bit of the knowledge they need. Not the whole thing.

Future research could aim at describing the workplace construction (target and aimed goals of business) in correlation with the personal trainer's values. There might be a difference between a chain fitness facility and a locally owned hometown gym, when it comes to providing that expert knowledge on a continual basis. 


\section{CONCLUSION}

While this study just scratches the surface on the proto-profession of personal training it helps organize literature and future organizational support for the occupational development. Understanding the role of the personal trainer from this research and previous emotional labor research, (Maguire, 2001) helps develop the overall picture of how the occupation could gain more legitimacy in the professional landscape. Personal trainers are currently placed in the fitness and health industry based on their work with the body. If personal trainers could clearly define their work with the body, it is possible to legitimize their work, placing themselves among the medical landscape. As one like John pointed it is working on one’s fitness but,

It's more of just working with that person on their wants I guess. If you are coming to a personal trainer you want to be more muscular. You want to be more cardiovascular. If you go to a physical therapist you have to, you actually need to be there.

This lines up with the changing trends and history of fitness, because people have faded away from previously used methods such as education in school but still acknowledge the ideals they need to maintain the "good citizen" projection in society.

There are differences between the "personal trainers" with respect to their educational attainment, experiences, techniques and practices, and their own perceptions of other "personal trainers." While the occupation is gaining steam, along with the entire fitness industry, it is starting to engage in movement to professionalization.

According to Abbott (1988), doctors are a profession but there is a drive in the division of labor for occupations to professionalize. Upon reflection, there are other methods for the "lay people” in society to gain knowledge about fitness and wellness. The "personal trainer” just tapped into that market (as a para-legal is aiding a lawyer) to aid in the development, reconstruction, and identity changing process related to the body. Providing these services is 
unique to personal fitness trainers, who also compete with other fitness industry products (i.e. videos, online services, etc) but highlight their psychological motivation and techniques as better than other market services. Matthew noted in regards to the future of personal training, "If we can get insurance to start paying for stuff like this I think that it could be one of the top professions out there but until we're covered with insurance when it comes out of pocket it's very difficult to get people to want to spend.” At this point, the occupation is such a contested terrain, in regards to practice, membership, education, and pathways to success; it remains an occupation in the fitness industry. While some of the personal trainers acknowledged the "professional academic work" and research by the affiliate organizations, these trainers are just practitioners who work on clients. Acceptance in the medical landscape might be plausible with a single unifying body focusing on occupational regulation and legitimization of fitness trainers. Either way, the "team concept" of social services (in this case health services) combines with medicine, and conflicted terrains is a characteristic among their practices. 


\section{REFERENCES}

Abbott, A. (1988). The system of professions: An essay on the division of expert labor. Chicago, IL: The University of Chicago.

Abbott, T. \& Eickhoff-Shemek, J. (2004). Legal issues in personal training. In R.W. Earle \& T.R. Baechle (Eds.). NSCA's Essentials of Personal Training. (607-626), Champaign, IL: Human Kinetics.

American Council on Exercise. (2012). Get certified. Retrieved from http://www.acefitness.org/getcertified/personal-trainer-certification.aspx

American Medical Association. (2012). About the American Medical Association (AMA). Retrieved from http://www.ama-assn.org/ama/pub/about-ama.page?

American Sports and Fitness Assocaiton. (2012). Personal training certification. Retrieved from http://www.americansportandfitness.com/collections/certifications/products/personaltraining-certification

Crawford, R. (1984). A cultural account of 'health.' Issues in the Political Economy of Health Care. (198-214). London, UK: Tavistock.

Crawford, R. (1980). Healthism and the medicalization of everyday life. International Journal of Health Services,10, 365-388.

Collins, R. (2004). Interaction ritual chains. Princeton, NJ: Princeton University Press.

Collins, R. (1979). The credential society. New York, NY: Academic Press.

Collins, R. (1975). Conflict sociology: Toward an explanatory science. New York, NY: Academic Press, Inc.

Corbin, J. \& Strauss, A. (2008). Basics of qualitative research: Techniques and procedures for developing grounded theory $\left(3^{\text {rd }}\right.$ e.). Thousand Oaks, CA: Sage Publications, Inc.

Department of Health and Human Services. (2009). Community-based partnerships for childhood obesity prevention and control: Research to inform policy.” Retrieved from http://grants.nih.gov/grants/guide/pa-files/PA-09-140.html

Dworkin, S.L. \& Wachs, F.L. (2008). Body panic: Gender, health, and the selling of fitness. New York, NY: New York University Press.

Epley, B. \& Taylor, J. (2000). Developing a policies and procedures manual. In T.R. Baechle \& R.W. Earle (Eds.). Essentials of Strength Training and Conditioning $\left(2^{\text {nd }}\right.$ ed.), (567585). Champaign, IL: Human Kinetics.

Foucault, M. (1977). Discipline and punishment: The birth of the prison. (A. Sheridan, Trans.). New York, NY: Vintage Books.

Giddens, A. (1991). Modernity and self-identity: Self and society in the late modern age. Cambridge, MA: Polity Press. 
Glassner, B. (1989). Fitness and the postmodern self. Journal of Health and Social Behavior, 30(2), 180-191.

Goffman, E. (1959). The presentation of self in everyday life. New York, NY: Anchor Books.

Goffman, E. (1963). Stigma: Notes on the management of spoiled identity. New York, NY: Simon and Schuster Inc.

Hughs, E.C. (1994). On work, race, and the sociological imagination. L.A. Coser (Ed.) Chicago, IL: University of Chicago Press.

Krotee, M.L. \& Bucher, C.A. (2007). Management of physical education and sport. (13 ${ }^{\text {th }}$ ed.). Boston, MA: McGraw Hill.

Lamonte, M. \& Molnar, V. (2002). The study of boundaries in the social sciences, Annual Review of Sociology, 28, 167-195.

Lasch, C. (1991). The culture of narcissism: The American life in an age of diminishing expectations. Revised Edition. New York, NY: W.W. Norton \& Company.

Maguire, J.S. (2001). Fit and flexible: The fitness industry, personal trainers, and emotional labor. Sociology of Sport Journal, 18, 379-402.

Manza, J. (1992). Classes, status groups, and social class: A critique of neo-weberian social theory. Current Perspectives in Social Theory, 12, 275-302.

National Exercise Trainers Association. (2012). Personal trainer certification. Retrieved from http://netafit.org/certification/personaltrainer.htm

Niederpruem, N. \& Sipe, C. (2006). Introduction to personal training. American College of Sports Medicine. ACSM's Resources for the Personal Trainer. ( $2^{\text {nd }}$ ed.). (2-15), Philadelphia, PA: Lippincott Williams \& Wilkins.

Reno, T. (2007). The eat clean diet: Fast fat loss that last forever! Ontario, CAN: Robert Kennedy Publishing.

Rose, N. (1999). Governing the soul: The shaping of the private self. $\left(2^{\text {nd }}\right.$ ed.). London, UK: Free Association Books.

Stein, H. (1982). Neo-Darwinism and survival through fitness in Reagan's America. The Journal of Psychohistory, 10,163-187.

Tan, A.J. \& Brignole, D. (2012). Million dollar muscle: A historical and sociological perspective of the fitness industry. San Diego, CA: University Readers, Inc. 


\section{APPENDIX A}

\section{INTERVIEW SAMPLE QUESTIONS}

- Could you describe for me what being a personal trainer is or what does a personal trainer do?

-What type of experiences highlights your definition of being a personal trainer?

-Obviously in your profession you work with clients. What type of clients do you work with? -Is there a difference between male and female clients?

-Is there a difference between younger and older clients?

-What do you do with your clients?

-Physical activity?

-Nutritional activity?

-Emotional activity?

-What type of goals do clients usually set? Are they realistic? How do you go about talking to the client about their needs?

-What do you talk about with your clients? (Personal life, fitness, etc.)

-Do your clients ever compare you to a televised personal trainer? (Aka: Jillian, Bob, Jack, etc.)

-How do you define success with your client/s?

-How long do you work with a client?

-Have you ever hurt a client either physically/nutritionally/emotionally?

-What if a client gives up on an activity and they are not willing to put in the effort, do you keep pushing them or is there a line drawn with your effort given to them as well?

-Have you ever "lost a client"? (Where they are tired of you or do not like you for some reason and choose a different personal trainer/facility?)

-What is the retention rate for clients? How long do they last or stick with the program? Do you keep modifying the program for them or do they just become a member of the gym at a certain point?

-How did you become a personal trainer/fitness professional?

-Did you go to school for this field?

-Are you certified in some area of this field?

-Does it matter if one is educated in this fitness field?

-Do they need a certification to be a personal trainer?

-Is experience more of an impact compared to education? 


\section{APPENDIX A \\ CONTINUED}

-What are the dynamics between you and your co-workers on a daily basis?

-Do you all interact outside of staff context or the institution in which you work?

-How do you market your specific skills to attract clients?

-What makes you different than other personal trainers/fitness professionals?

-Are you ever evaluated at your job? If so who does the evaluations, the staff, the clients, or both?

-What is the importance of a personal trainer in today's society?

-If you had to defend your job today to people, what are a few words you would say about your objectives and outcomes for them? 


\section{APPENDIX B}

\section{EXTENDED PROFILES}

\section{Paul- Respondent 1}

Paul works at a facility which concentrates on variable athletic programming for athletes and other customers. It is a regional fitness center organized around the basis of intense training with shorter rest periods between exercises. He had been working in the field for two years prior to the interviews. He attributes his interest in the personal training field to the athletic activities he participated in throughout his childhood and in college. Educationally he earned a Bachelor's in Exercise Physiology and a Master's in a field related to coaching athletics and education. Paul is a member of a nationally known organization concentrating on athletic conditioning and development along with strength for athletes. His purpose in getting that certification was to become a strength coach someday at a high school or college.

\section{David-Respondent 2}

David worked at a locally owned gender specific fitness facility. At the time of the interview David had been working as a "personal trainer" for four years, which ended about one month prior to the interview. He was currently in school working on his bachelors related to information technology. The experiential learning he acquired from his boss has helped guide him in his personal trainer work. Before working in the locally owned location he did "take a personal training course" in a franchised gym located in another state. As far as continuing in this field David mentioned the following, "I'm pretty much done with my involvement in the fitness world except for my own personal edification, continued knowledge and growth uhh...and training myself."

\section{Bradley-Respondent 3}

Bradley is employed at a locally owned fitness facility which combines other occupations in the medical landscape, including fitness, physical therapy and rehabilitation, sport specific athletic skills training, and personal fitness training. He began his employment at this facility as an intern during his undergraduate studies' internship program. After the completion of his bachelor's degrees in exercise physiology and health science he was employed as a staff member at the facility, and has been upgraded from a staff member to the manager of the fitness section. He has a First Aid and CPR certification but no personal training certifications or certificates. He attributes his knowledge of personal training to the classes he took as an undergraduate and the "overshadowing" (by which he meant shadowing or watching) of the employers.

\section{Sarah-Respondent 4}

Sarah was the first of three respondents who shared the other occupational development they have along with their personal training. She has been working in the medical landscape as another para-professional (nurse) while also being a personal trainer. Sarah earned her bachelor's degree in exercise physiology and also obtained three certifications related to personal training (personal training, nutritional consultations, and group fitness) from an organization. Sarah has been working in the personal training field for five years and has 


\section{APPENDIX B}

\section{CONTINUED}

worked at two different facilities. She currently is employed at an in-house servicing facility related to the fitness, rehabilitation, and athletic development. She is the only respondent with the personal trainer certification from the Professional Fitness Association. She wanted "all three certifications," previously mentioned, "to come from the same organization" and other organizations could not do that. Sarah, along with one other respondent (Andrew), is adamant about the influence of nutrition on a client's success with fitness, that " $80 \%$ is nutrition and $20 \%$ is workout."

\section{Zach-Respondent 5}

Zach is a certified athletic trainer and "is not going to say he is a personal trainer but the knowledge can cross-over." He works, as an independent contractor, at a franchised fitness facility which caters to the general population all hours of the day. In three years he has been employed at two different facilities working his way from "the front desk" to being a "personal trainer" to clients. At the time of the interview he was in the process of hiring a female to assist him in being a "personal trainer" to clients, as a part of his business. Zach has aspirations of going to medical school and uses the knowledge of the body and its functioning to aid in the success and knowledge attainment of his clients, "the way I see it, I'm being 100 percent efficient. Telling them every little thing I know as opposed to a personal trainer who you can have a high school diploma. .... You know what I mean. I have a sport and exercise science degree and you have to have that to add value to the market place."

\section{Timothy-Respondent 6}

Timothy is fitness director in an in-house fitness facility and uses his background in physical rehabilitation to aid his clientele. His interest in working out and fitness started when he was a young child and he realized "I've kind of always wanted to be a trainer." He earned his bachelor's and master's degree in exercise physiology and has worked in multiple settings related to aquatic therapy, rehabilitation, personal training, and corporate wellness and fitness. Timothy is one of the more tenured respondents, sharing his experiences of 14 years in the personal training and fitness industry. He understands the certification process of personal training (which he commented was "hokey enough in itself, because who says who is qualified?") and mentioned the following, "But it's generally the biggest and the medically supported ones are generally the ones you know, say the ones who have gotten pretty big to where they do a lot of research and stuff." He is certified in strength and conditioning along with a smaller body building certification and uses both to attract a variety of clients.

\section{Matthew-Respondent 7}

Matthew works as an independent contractor at a franchised fitness facility which caters to the general population all hours of the day. His background of working in the fitness industry ranges back 10 years. While working at a fitness facility in college, Matthew earned his bachelor's degrees in exercise physiology and nutrition along with a master's degree in exercise physiology. After working at the facility in college, he opened up his own business and ran that for a few years before being offered his current position as an independent contractor. Matthew 


\section{APPENDIX B}

\section{CONTINUED}

has experience and a certification in body building along with being a certified personal trainer. During the interview Matthew shared a good deal of experience on the business side of his occupation and identified himself as a "personal trainer, exercise physiologist, and nutritionist."

\section{Kathleen- Respondent 8}

Kathleen provided the longest interview of all the respondents. She shares a different perspective and is highlighted throughout the research because of her experience as an educator of personal trainers. Kathleen has a bachelor's in physical education teacher education and health and a master's degree in physical education and teacher education. She has been "training trainers for about the past 15 years." She has been a part of the fitness industry for over 30 years, as representative of the National Exercise Council, and has seen a lot of changes. As a teacher she offered insight into the field and the organizational structure. "I think what makes, I'm just a teacher. My master's is in teaching, I love teaching. And teaching these kids how to be personal trainers is just such a joy to see them get confident and umm go out and just be ready to go, ready to train. Because it's hard to do it by yourself although a lot of people do buy the book, then study, then go take the test." She also gave an emphasis on teaching the clients about fitness and wellness.

\section{Carly-Respondent 9}

Carly is a 15 year veteran in the field of personal training and fitness. She earned her bachelor's degree and master's degrees in athletic training and sports medicine. After her undergraduate studies she was offered a job as a "personal trainer" because she had an education in athletic training and sports medicine the company offered to pay for her personal training certification through the National Exercise Council. She had a basic fitness testing certification from the National Sports Medicine College but now has a certification from the organization Paul has his certification through, concentrating on athletic conditioning and development along with strength for athletes. Carly mentioned the specialties she has in concentrating on student-athletes for athletic training and also as a personal trainer, working with the geriatric population.

\section{Jane-Respondent 10}

Jane is one of two respondents who are studying to be personal trainers or another occupation in the medical landscape. She is in school working on a "dual degree in exercise physiology and athletic training." Upon graduation she will have two bachelor's degrees and during the time of the interview she had passed her oral examination for a personal training certification and was waiting to hear back about the written examination. Because she was an intern at a fitness facility, that organization paid for her to take the examination for the personal trainer certification from the National Exercise and Aerobics Association. From her student's perspective she was able to explain how she had learned more from the athletic training program than from the exercise physiology program, "In athletic training it's not hard but we 


\section{APPENDIX B}

\section{CONTINUED}

practice it every day. You pretty much have a full time job on top of going to school. I mean you're in the athletic training room 30-40 hours a week on top of taking classes. It's probably not as hard because we are constantly practicing what we learn. Ex. Phys. you don't practice what you learn. You learn it, you memorize it, you take a test. So umm, I'd say which one you benefit from more, athletic training beyond ex. Phys. Completely. Like I've learned more in the past year and a half of being in athletic training than four years that I did in exercise physiology." She was working on plans to intern during the summer months and apply for graduate school in athletic training or as a physician's assistant.

\section{John-Respondent 11}

John is also a student studying to earn a bachelor's in exercise physiology. He works at the same facility that Jane does as a personal trainer. John is studying and working as a personal trainer to get experience in helping clients because he plans to become a physical therapist. He did offer insight on what someone could do if they wanted to become a personal trainer.

\section{Andrew-Respondent 12}

Andrew is a respondent who has also spent a long time in the fitness industry, a total of 24 years and counting. He does not have a degree in exercise physiology but, "I've spent years of my life learning from professionals in the industry. I've traveled the world to seminars with actual people that succeed in fitness not people who educate people in fitness." Andrew owns his own fitness facilities and is a franchise owner of a nutritional program also. He is one of the lead respondents who advocate for nutrition as more important than the fitness and exercise portion. Andrew does not have any certifications but is adamant about his experience in the fitness industry throughout the years. 